دراسة خصائص المياه الأرضية والتزبة في منطقة بلطيم

\author{
إعداد \\ ريهام صلاح عبد الونيس أبو السعود \\ طالبة ماجستير بقسم الجغر افيا- كلية الآداب- جامعة دمياط
}




\section{دراسة خصائص المياه الأرضية والتربة في منطقة بلطيم}

ملخص البحث:

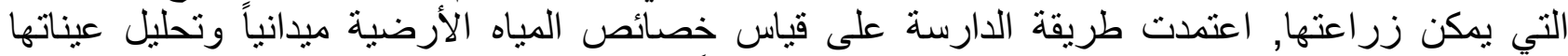

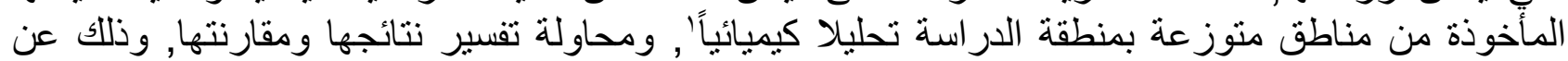

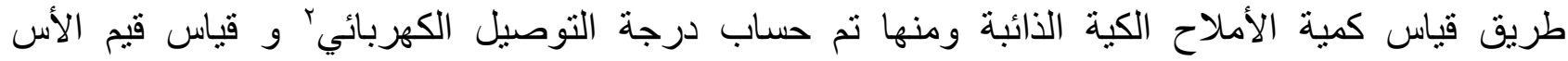

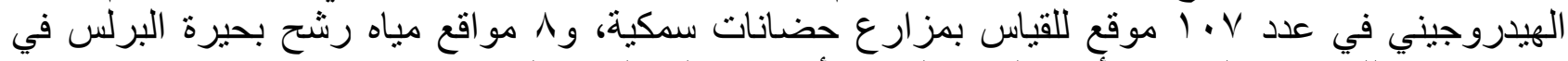

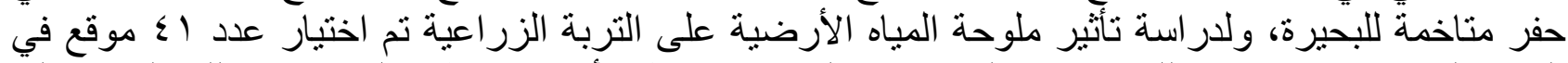

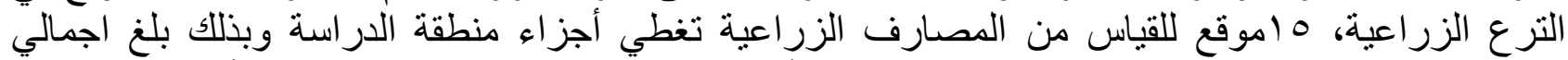

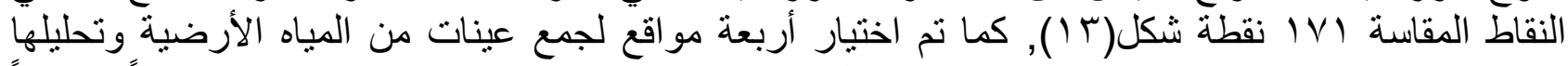

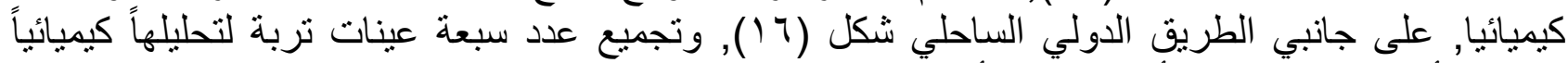

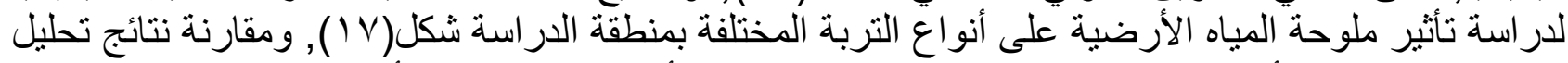

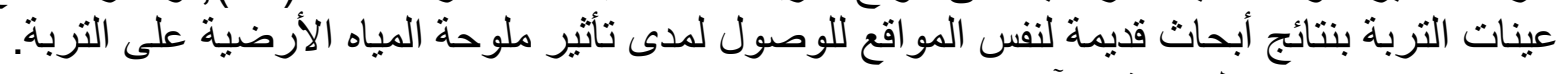

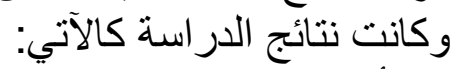

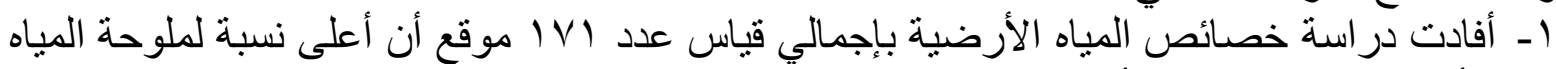

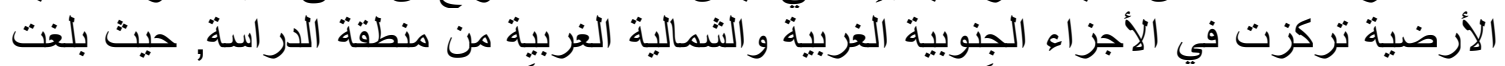

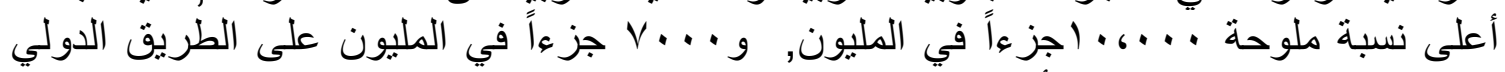

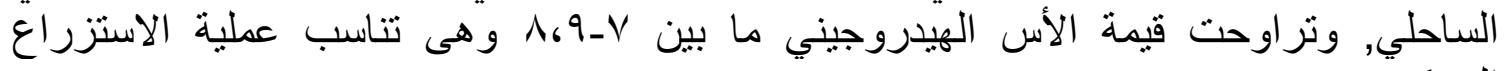

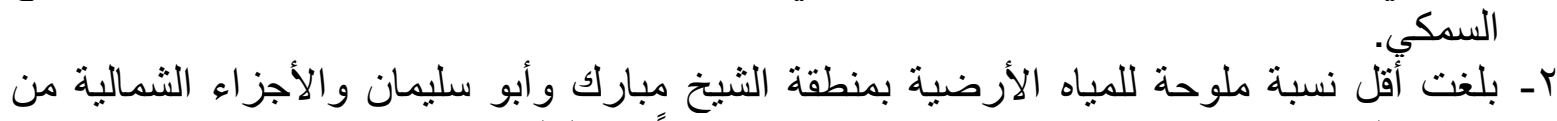

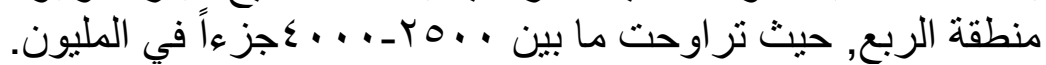

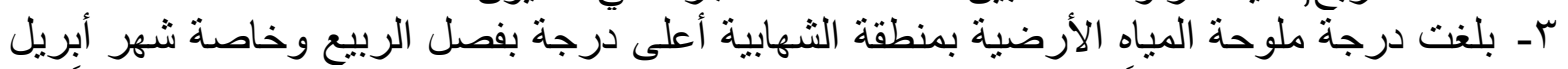

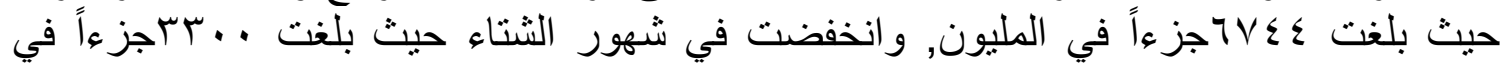

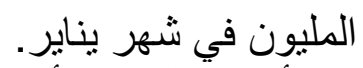
ــ كما أفادت الدر اسة أن العلاقة بئة بين ملوحة المياه الأرضية ودرجة الحرارة بمنطقة الربع هي علاقة

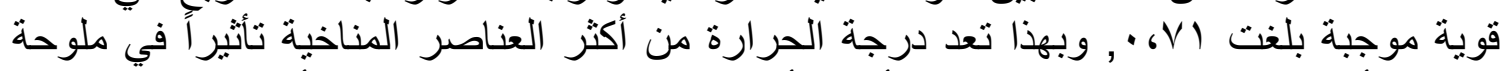

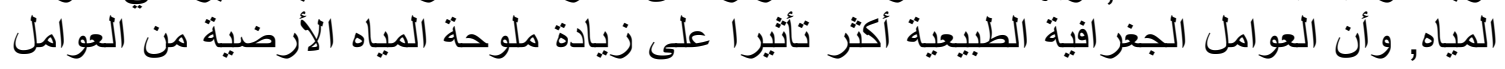

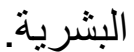
ــ اختلاف ملوحة التربة بمناطق الدراسة المختلفة, حيث بلغت ملوحة التربة بمنطقة الربع حوالي

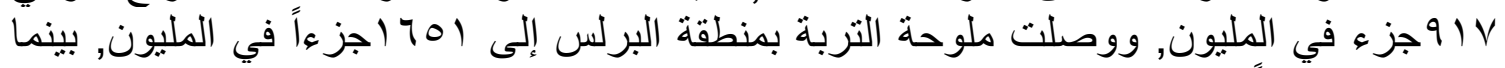

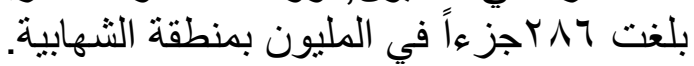

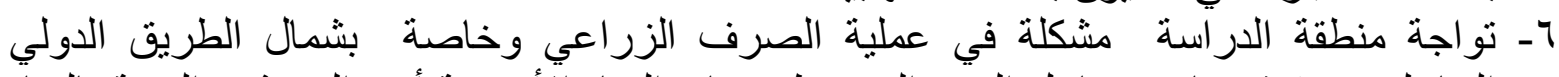

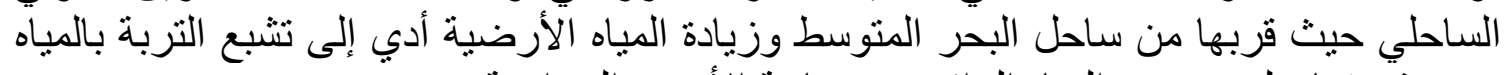

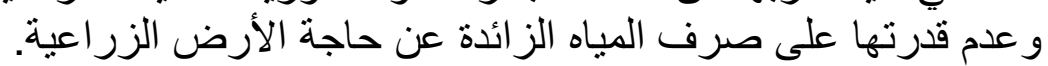

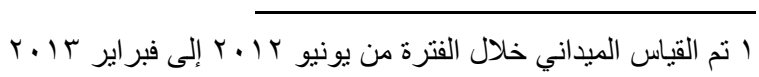




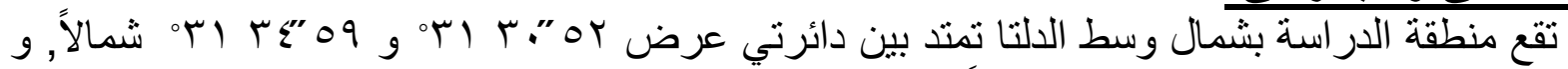

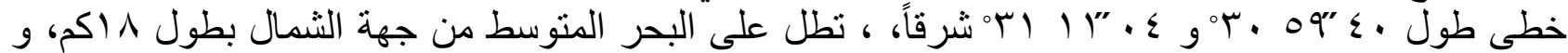

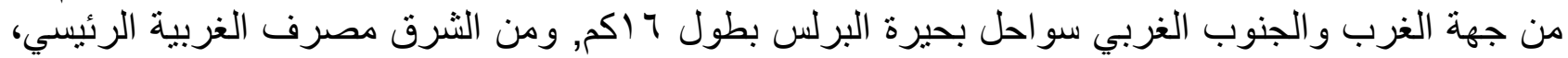

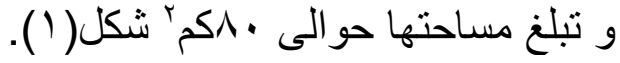

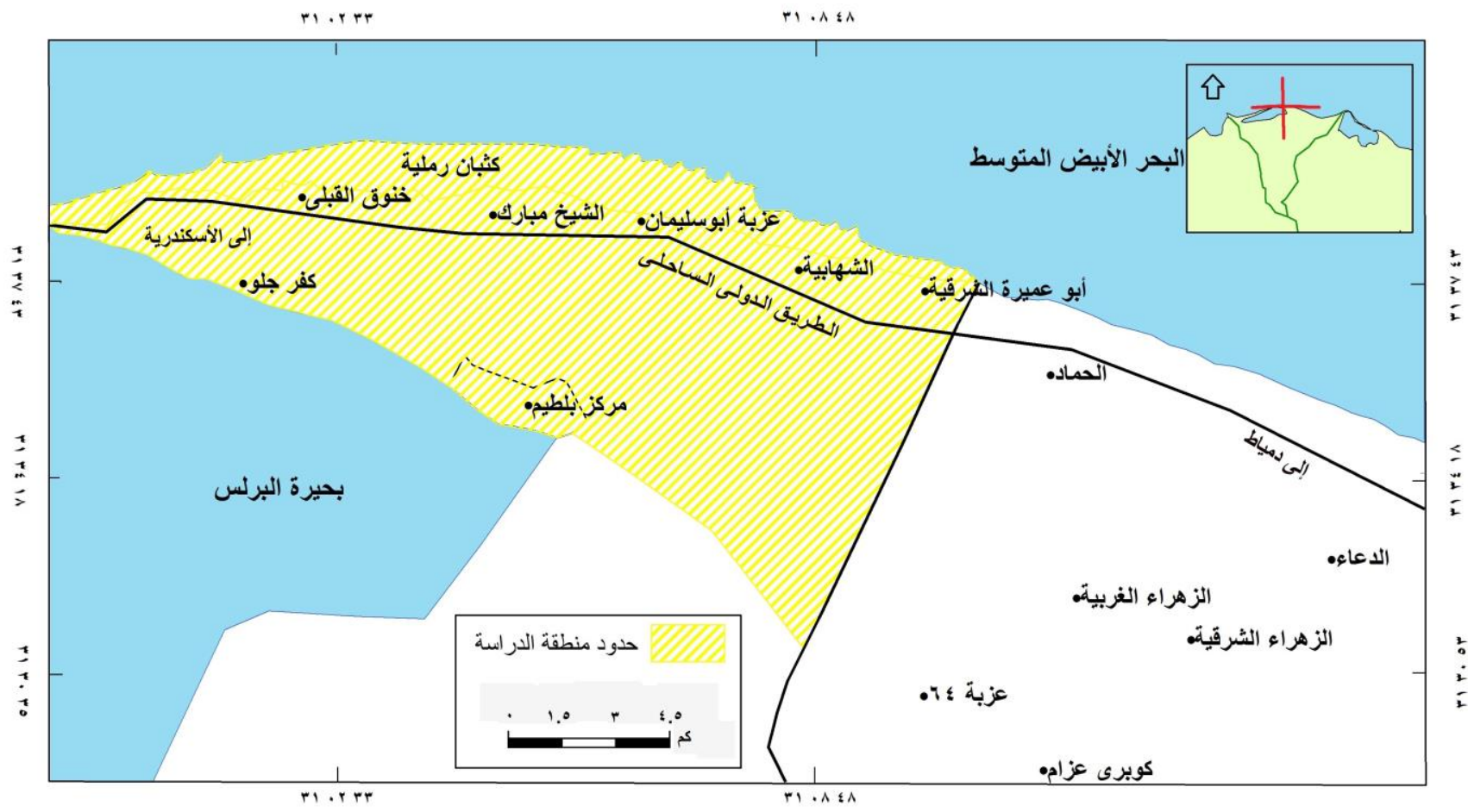

شكل( (1) موقع منطقة الدر اسة

$$
\text { بلطيم - ملوحة المياه الأرضية: }
$$

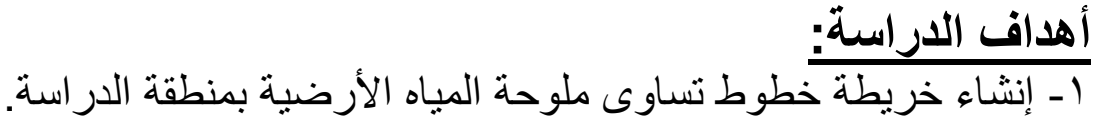

r- در اسة تأثثير التغير ات المناخية على ملوحة المياه الأرضية والتئة التربة.

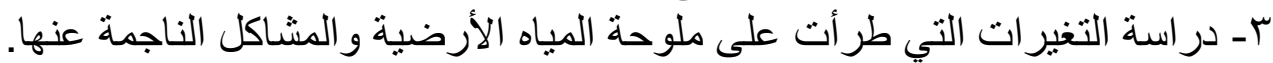

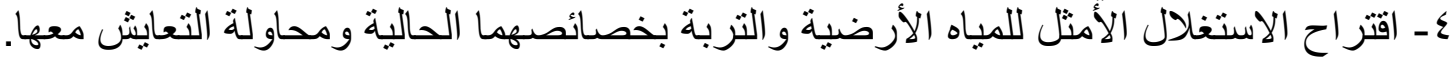

مقدمة: تعد كلا من المياه الأرضية و الترية بمنطقة بلطيم عنصر ان مؤثران على أنظمة الحياة بمنطقة الدراسة, حيث ارتفاع نسبة الملوحة المعاصرة في المياه الأرضية و التربة السطحية, أدت إلى عرقلة الألة الأنشطة البشرية

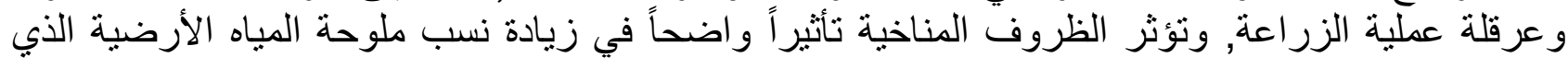
يوثر على تملح التربة وضعف إنتاجيتها, حيث يؤدى الارتفاع في درجة الحرارة على مدار شهور الصيف إلى تبخر المياه وترسب الأملاح. 
تتمثل مشكلة البحث في زيادة نسب ملوحة المياه الأرضية بمنطقة بلطيم, وخاصة في الجزء الثئ الشمالي من الطريق الدولي الساحلي, وذللك بناء على قياسات قامت بإجر ائها الطالبة وتتمثل في قياس كمية الأملاح

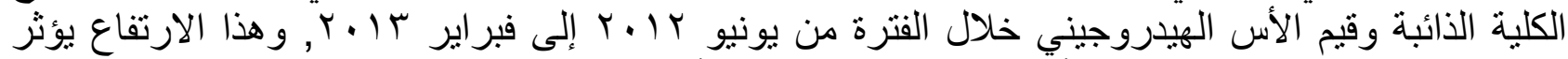

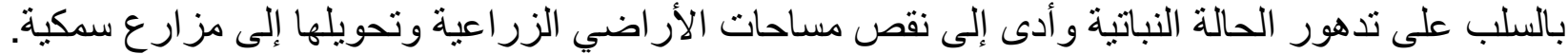

الأر اسات السابقة:

تناول العديد من الباحثين در اسة ملوحة المياه الأرضية والأر اضي المتأثرة بالملوحة بجمهورية مصر

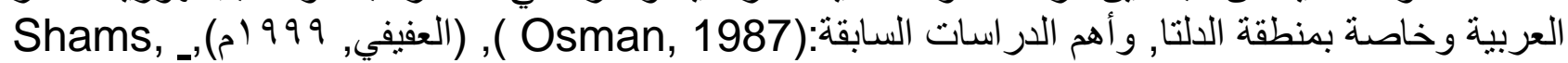

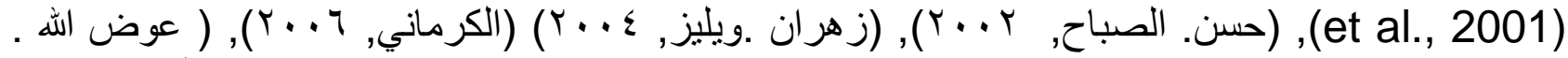

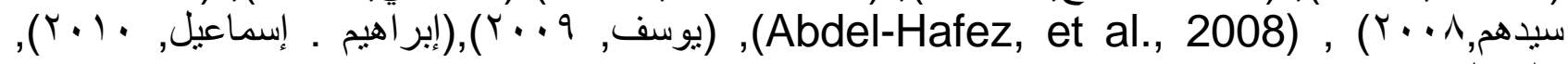

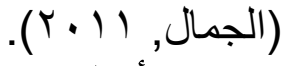

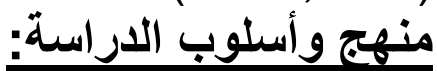
( أ ) المناهج: اعنمدت السفوب الدراسة على عدد من المناهج البحثية ذات الصلة بموضوع الدراسة, متمثلة في المنهج الإقليمي حيث قامت الطالبة بدر اسة منطقة محددة جغر افيا, ويمتاز هذا المنهج بأنه يبرز الثخصية

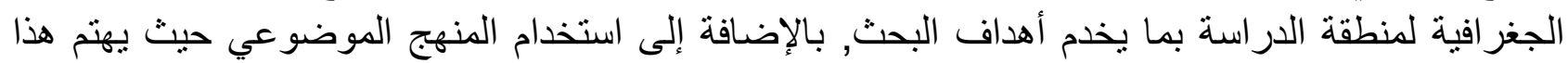

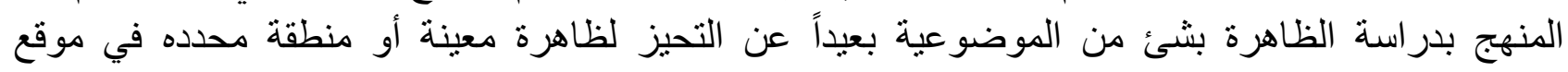
الدر اسة, وأخيرا استخدام المنهج التاريخي ويهدف استخدام هذا المنهج إلى التعرف على على التغير ات التئ التي حدثت لملوحة المياه الأرضية خلال الفترة الزمنية للار اسة بالإضافة إلى الظروف المناخية, و أثرها على النشاط البشرى.

(ب) أساليب الدراسة: استخدمت الطالبة أسلوب الدراسة الميدانية لقياس التغيرات التي طرأت على المياه

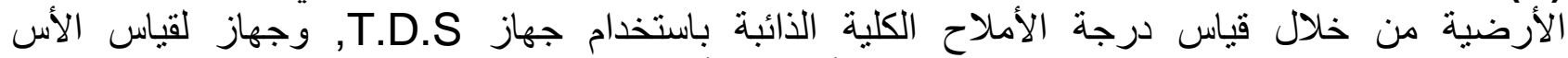
الهيدروجيني Ph، وجهاز Gps لتحديد مواقع الأشكال الأرضية ومواقع عينات الرواسب, وقامت الأت الطالبة

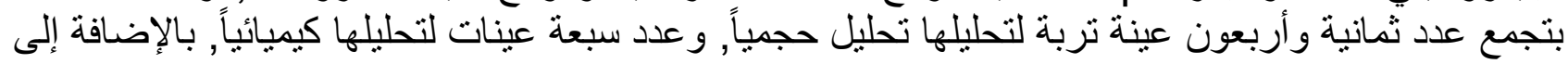

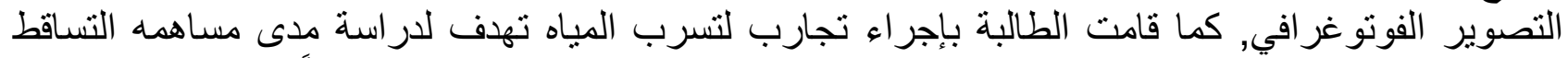
الحالي في تغذية المياه الجوفية, ويستفاد منه في معرفه مدى توغل مياه البحر تحت سطحياً.

الخصائص الطبيعية لمنطقة الدراسة: المئية الخصائص المناخية: تعد الحرارة من أهم العناصر المنائهة المناخية المؤثرة في القيمة الفعلية للتساقط الذي يؤثر بدوره

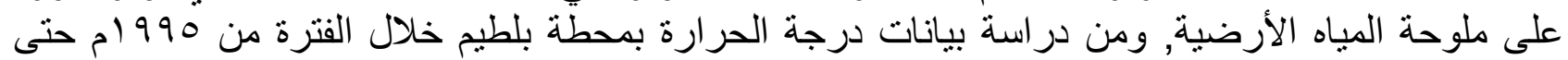

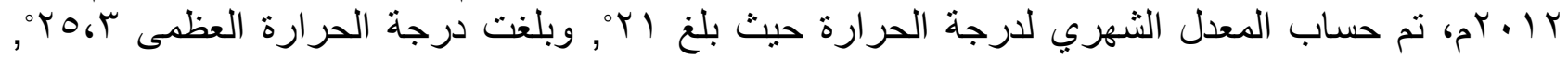

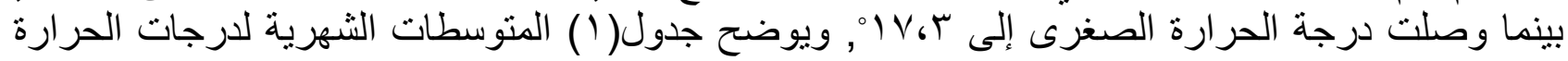

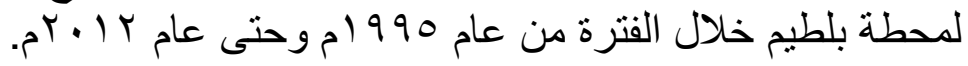


جدول ( (1) معدلات درجات الحرارة بمحطة بلطيم

\begin{tabular}{|c|c|c|c|}
\hline الصغرىه & العظمي & المتوسط الشهري & الشهر - مار \\
\hline 1.67 & $111_{6} \mathrm{~V}$ & $1 \varepsilon_{6} \pi$ & يناير \\
\hline 11 & 19 & $1 \varepsilon 67$ & فبر اير \\
\hline $1 r_{6} 0$ & r) & 17,4 & مارس \\
\hline 10 & rr & 19 & إبريل \\
\hline 11 & YT، & YI.V & مايو \\
\hline$r \cdot 6)$ & rq & $r 0,1$ & يونيو \\
\hline$r \varepsilon$ & rI & TV. & يوليو \\
\hline$T \varepsilon_{6} \varepsilon$ & TI. T & YY.T & أغسطس \\
\hline Tr & $r \cdot . r$ & r7, r & سبتمبر \\
\hline$r$. & rV.7 & $r 0, r$ & أكتوبر \\
\hline 17.0 & $r \leq 6 r$ & $r$. & نوفمبر \\
\hline $1 r_{6} 0$ & Tr & 17.1 & ديسمبر \\
\hline $1 V_{6} r$ & ro,r & r) & المتوسط العام \\
\hline
\end{tabular}

مصدر البيانات:http:/www.weatheronline.co.uklweatherlmapslcity.htm, و المتوسطات من حساب الطالبة

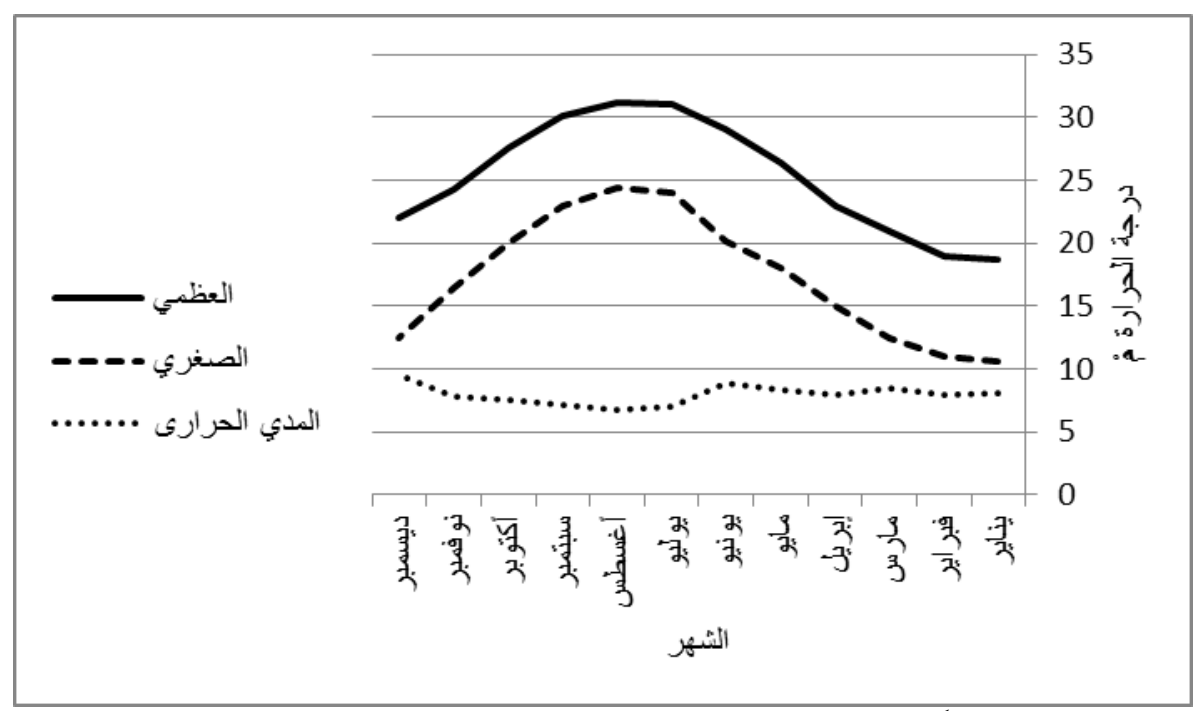

مصدر البيانات: من عمل الطالبة إعتماداً على جدول ( ( )

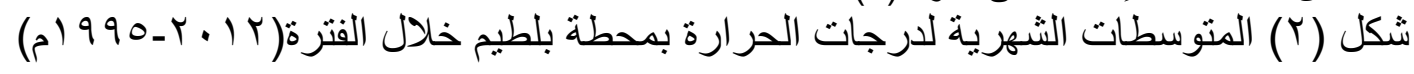

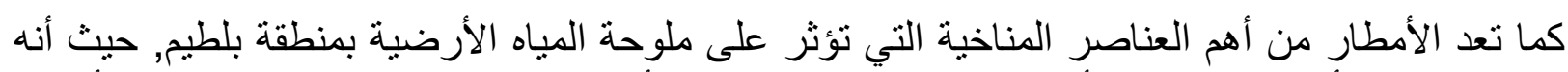

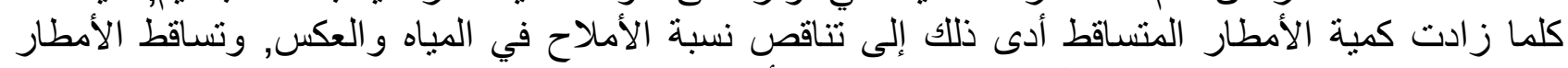

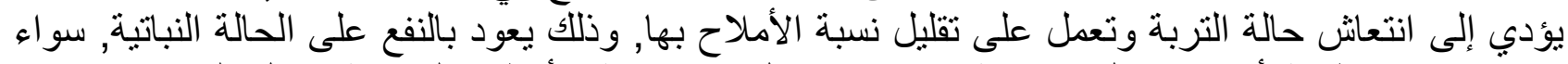

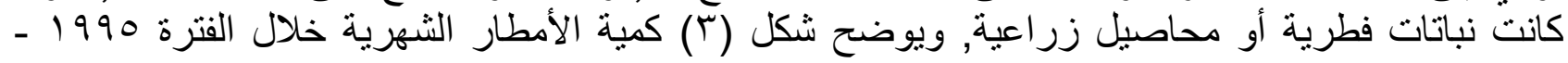

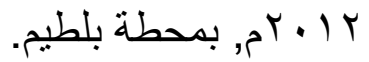




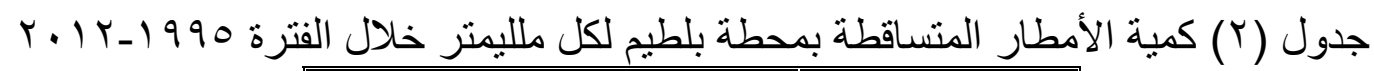

\begin{tabular}{|c|c|}
\hline كمية الأمطار المتساقطة / ملم & الثهر \\
\hline$r 96 r$ & يناير \\
\hline$r \varepsilon_{6} \wedge$ & فبر اير \\
\hline IYGV & مارس \\
\hline r.9 & إبريل \\
\hline .69 & مايو \\
\hline صفر & يونيو \\
\hline .619 & يوليو \\
\hline صفر & أغسطس \\
\hline .61 & سبتمبر \\
\hline 0,1 & أكتوبر \\
\hline 9.7 & نوفمبر \\
\hline TYG & ديسمبر \\
\hline 1167 & المعدل \\
\hline
\end{tabular}

مصدر البيانات: http://www.weatheronline.co.uk/weather/mapslcity.htm

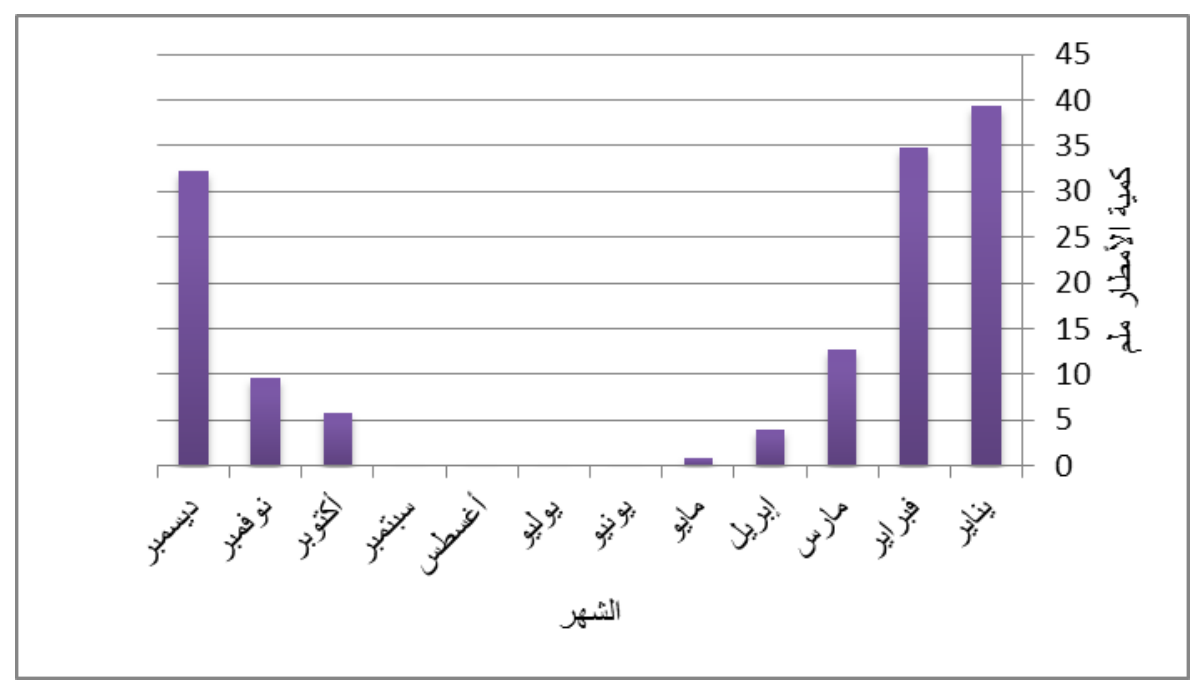

مصدر البيانات : من عمل الطالبة إعنماداً على جدول (r) (r)

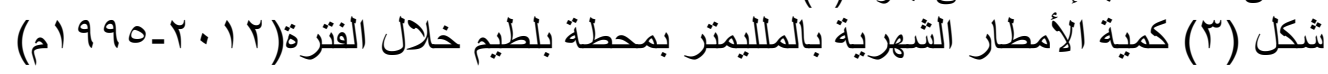

يتضح من تحليل جدول(r), وشكل (ب) الآتي:

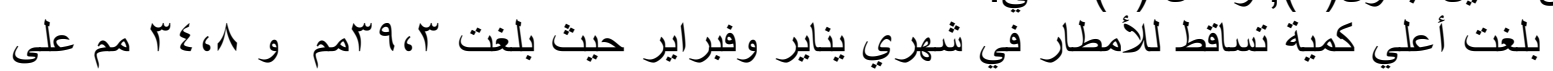

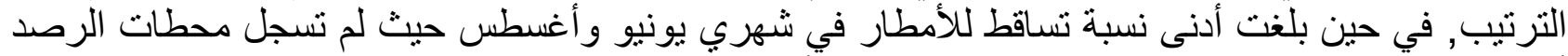

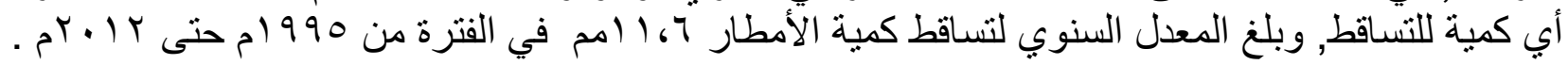


التربة وتصنيفها: افادت دراسة التربة أنه يوجد بمنطقة الدراسة أربع أنواع من التربة أولى التربة الرملية

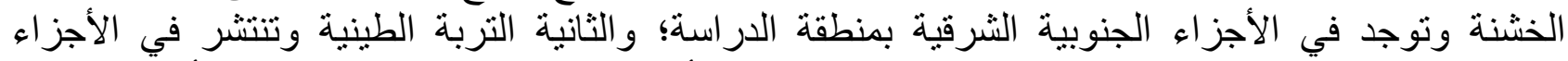

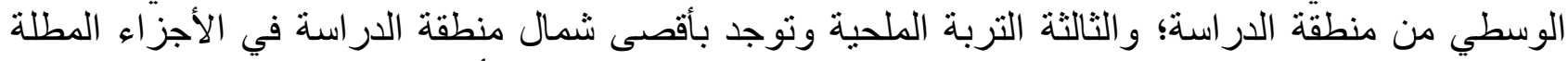

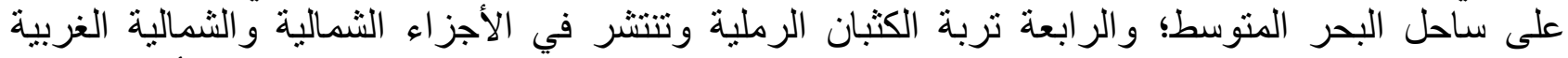

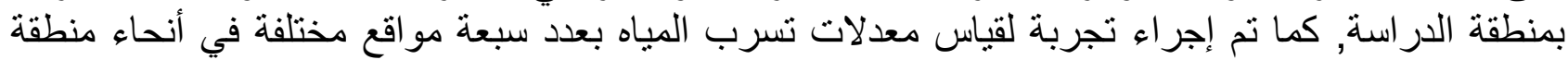

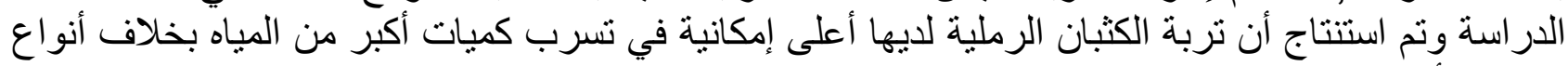

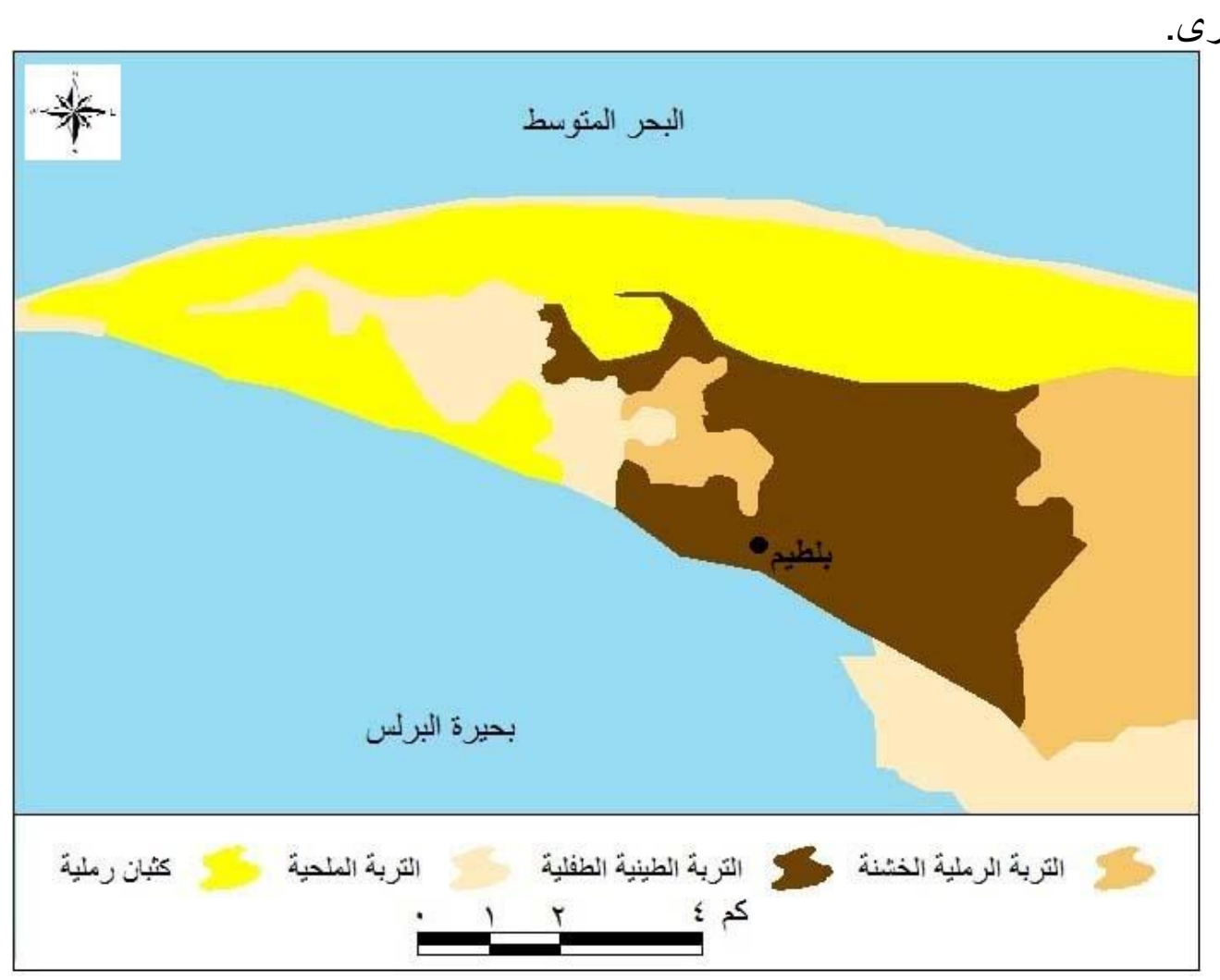

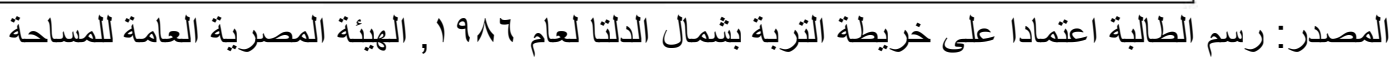

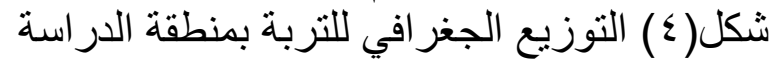

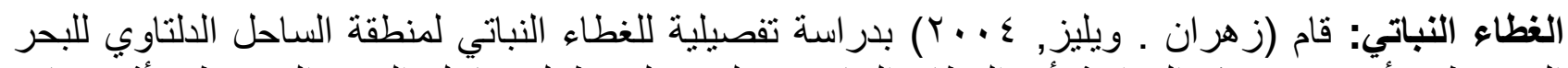

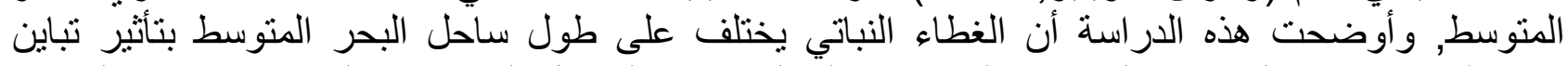

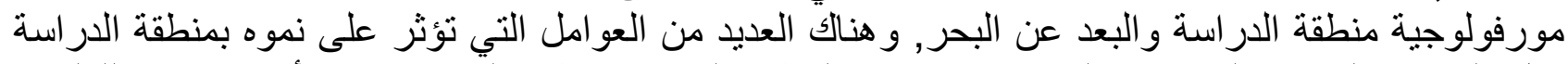

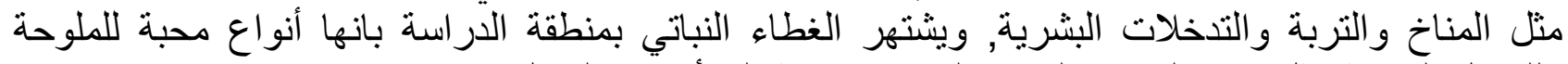

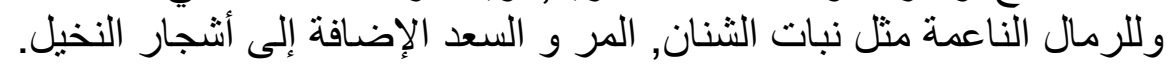

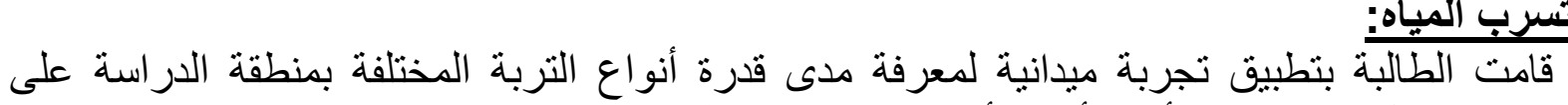

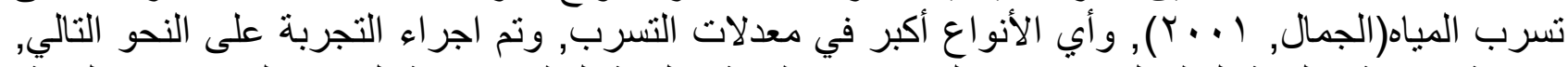

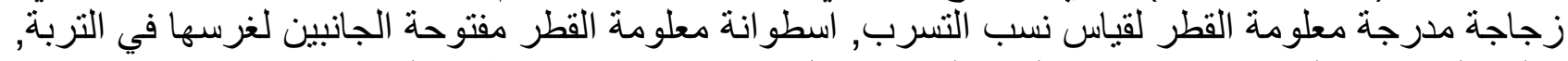

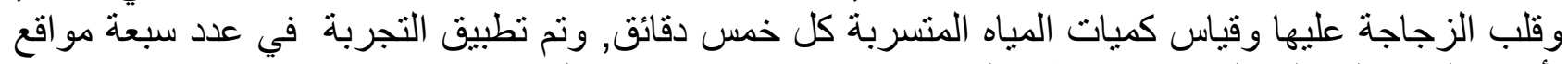
بأنو اع التربة المختلفة الموجودة بمنطقة الدراسة كما هو موضح في شكل (V) 


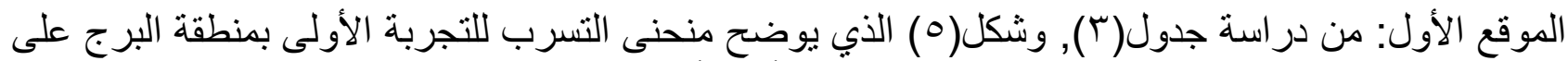

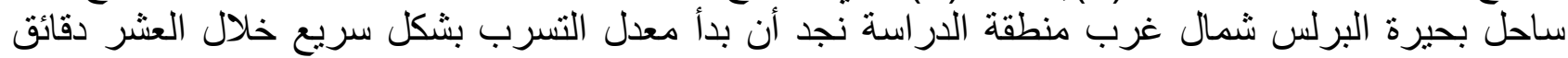

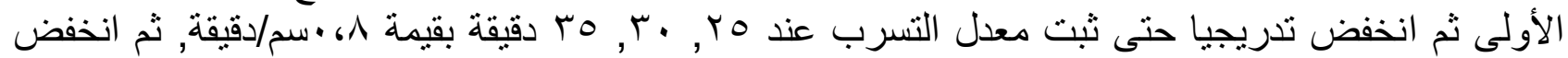
حتى وصل معدل التسرب إلى Vا، •سم/دقيقة, وترجع هذه النسب المنخفضة في معدلات التسرب إلى إنها تربة

\begin{tabular}{|c|c|c|c|c|c|c|c|c|}
\hline$\varepsilon$ & ro & $r \cdot$ & ro & $r$. & 10 & 1. & 0 & الزمن(دقيقة) \\
\hline $.6 \mathrm{~V}$ & .61 & .61 & $.6 \wedge$ & 1,4 & 1 & 1,1 & $r$ & معدل التسرب(سم/دقيقة) \\
\hline
\end{tabular}

المصدر: من حساب الطالبة اعتماداً على الدر اسة الميدانية

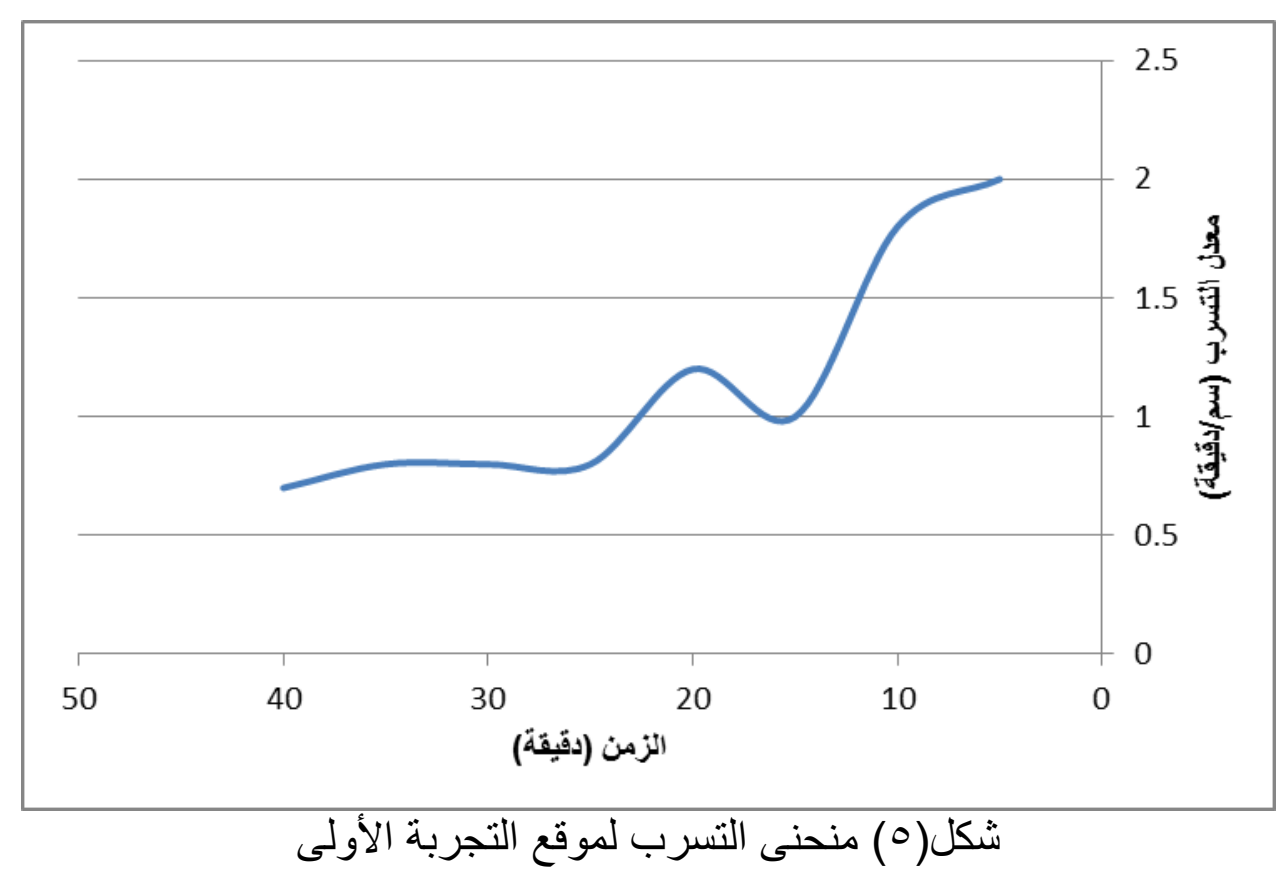

الموقع الثاني: من دراسة جدول(ع) وشكل(؟) الذي يبين معدل التسرب بالتجربة الثانية نستنتج أن التربة تثبعت بالمياه بعد مرور 0 كدقيقة وكان معدل تثبعها يتناقص بنسبة ضئيلة بعد مرور أول عشر دقائق.

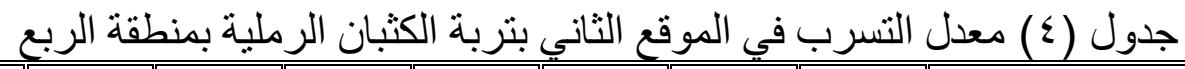

\begin{tabular}{|c|c|c|c|c|c|c|c|c|c|}
\hline$\varepsilon 0$ & $\varepsilon$. & ro & $r$. & ro & $r$. & 10 & 1. & 0 & الزمن (دقيقة) \\
\hline $.6 \mathrm{~V}$ & $.6 \mathrm{~V}$ & .61 & $\cdot$ • ^ & 1 & 161 & 1 & 1 & $\left.\varepsilon_{6}\right)$ & معدل التسرب(سم/دقيقة) \\
\hline
\end{tabular}

المصدر: من حساب الطالبة اعتماداً على الدر اسة الميدانية 


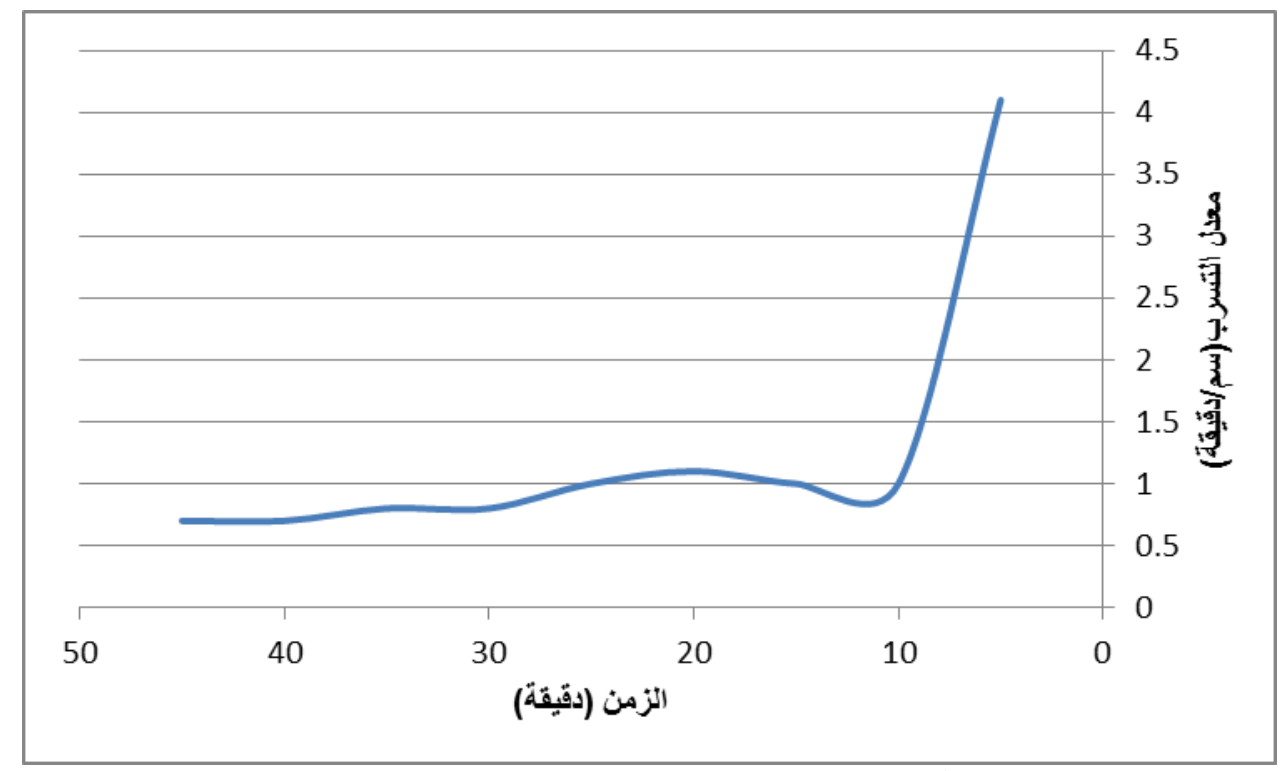

شكل(T) منحنى التسرب لموقع التجربة الثانية

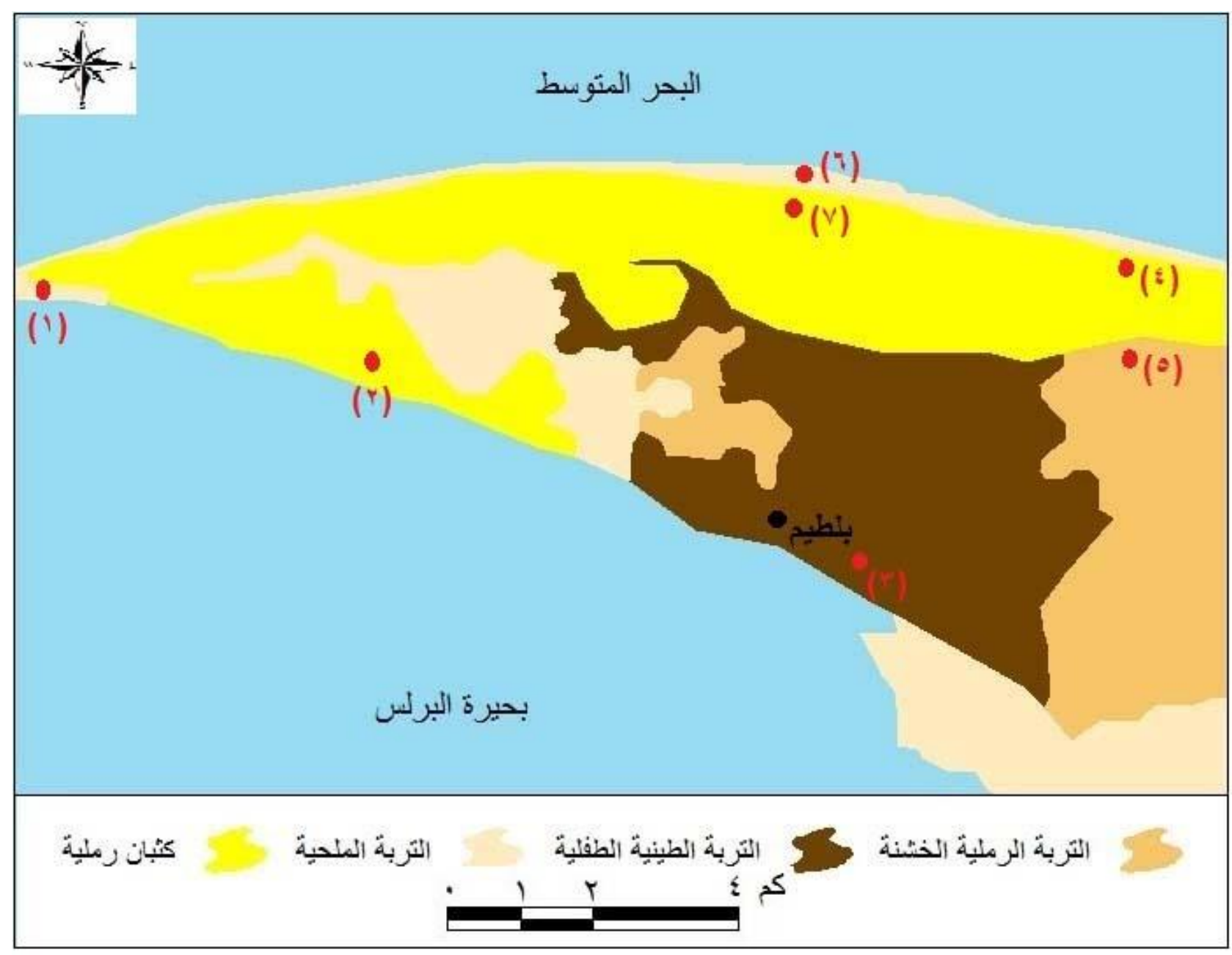

شكل(V) التوزيع الجغر افي لمو اقع إجراء تجارب معدلات التسرب 


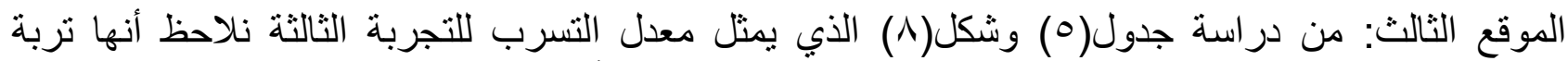

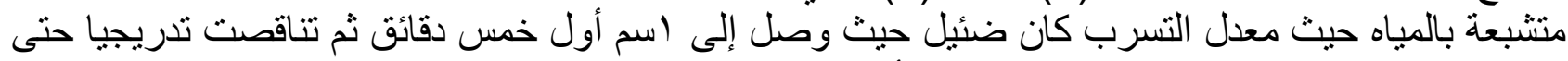

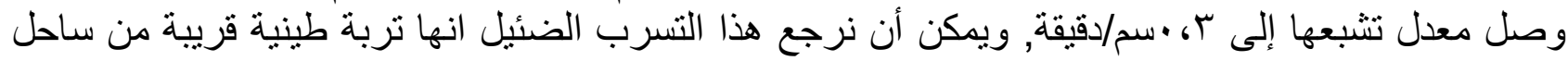
بحيرة البرلس مشبعة بالمياه المتسربة إليها من البحيرة.

جدول (0) معدل التسرب في الموقع الثالث في التربة الطينية الطفلية بمنطقة بلطيم

\begin{tabular}{|c|c|c|c|c|c|c|}
\hline r. & ro & r. & 10 & 1. & 0 & الزمن (دقيقة) \\
\hline $.6 \mathrm{~T}$ & $.6 \mathrm{r}$ & .64 & . . & .60 & 1 & معدل التسرب(سم/دقيقة) \\
\hline
\end{tabular}

المصدر: من حساب الطالبة اعتماداً على الدراسة الميدانية

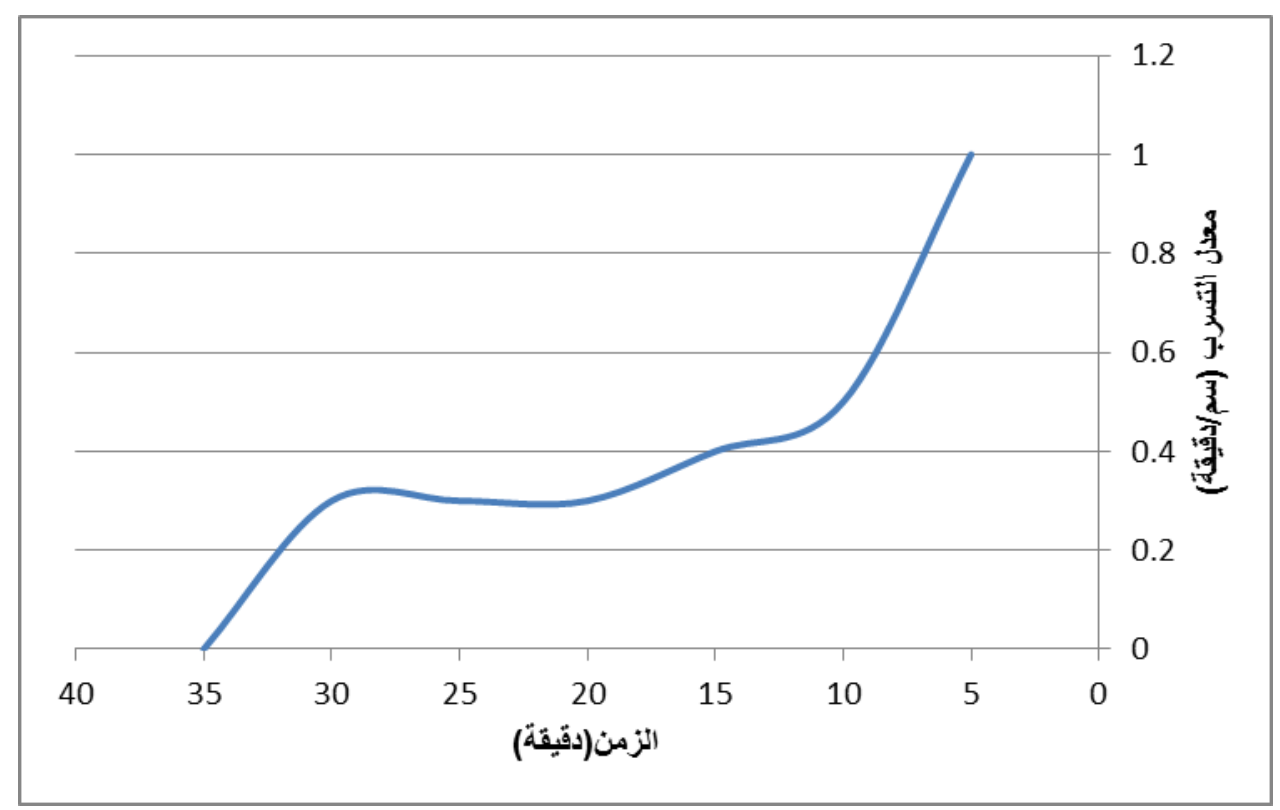

شكل(^) منحنى التسرب لموقع التجربة الثالثة

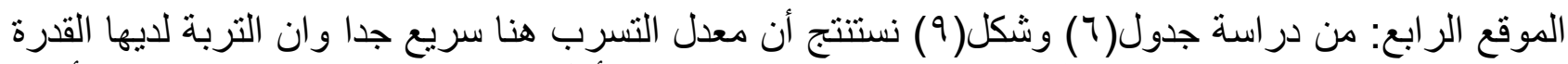

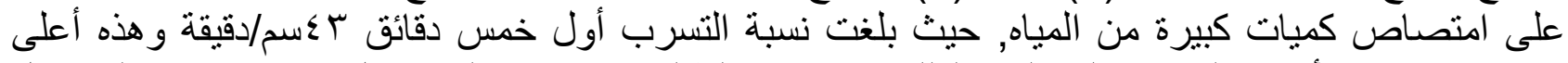
نسبة تسرب في أنواع التربات المختلفة ولذلك فقد قامت الطالبة باحتساب الوقت كل دقيقة واحده وليس كل الت الت جدول (T) معدل التسرب في الموقع الرابع في تربة الكثبان الرملية بقرية الثهابية

\begin{tabular}{|c|c|c|c|c|c|c|c|c|c|c|c|c|c|}
\hline IT & IT & 11 & 1. & 9 & $\Lambda$ & V & 7 & 0 & $\varepsilon$ & 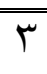 & $r$ & 1 & الزمن (دقيقة) \\
\hline $\bar{r}$ & $\varepsilon$ & $\varepsilon$ & $\varepsilon$ & $\varepsilon, 0$ & 0 & 0 & 0 & 0 & $\bar{v}$ & $\bar{\Lambda}$ & 1 & 10 & معدل التسرب(سم/دقيقة) \\
\hline
\end{tabular}

المصدر: من حساب الطالبة اعتماداً على الدراسة الميدانية 


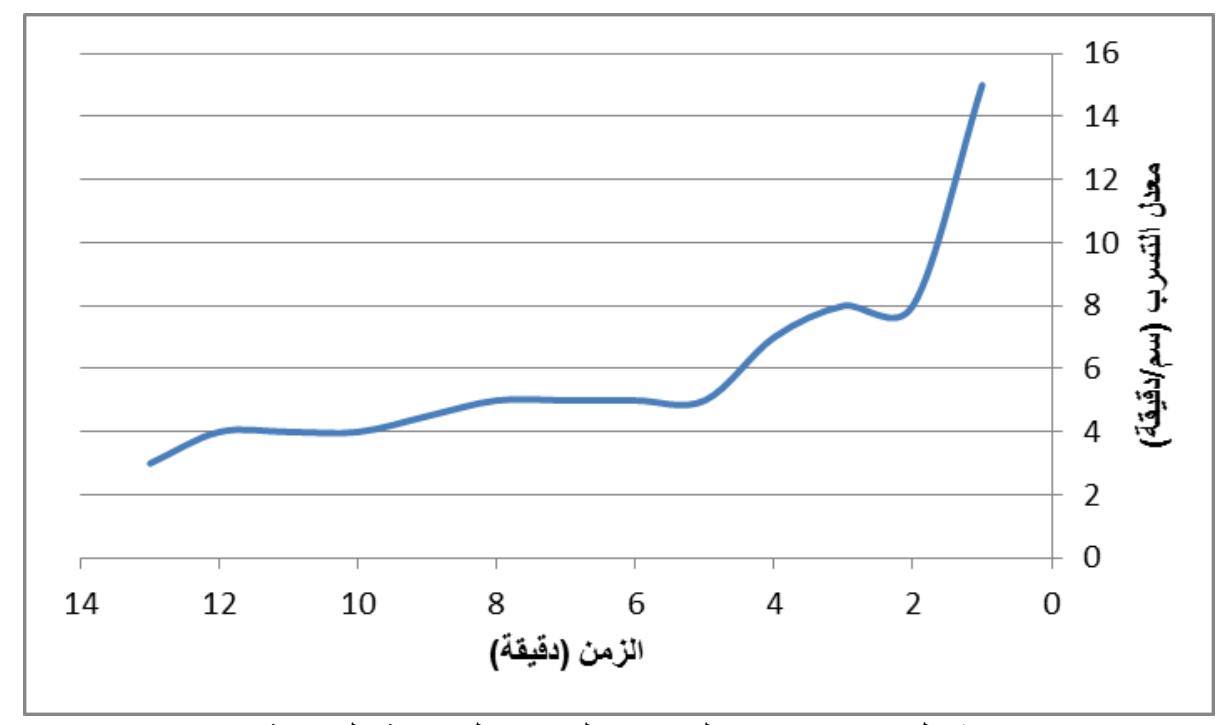

شكل(9) منحنى التسرب لموقع التجربة الرابعة

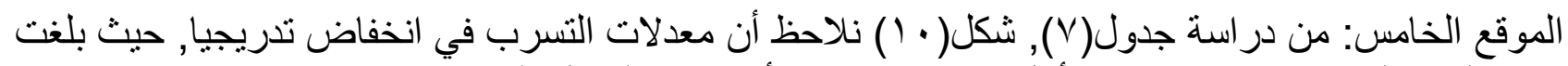

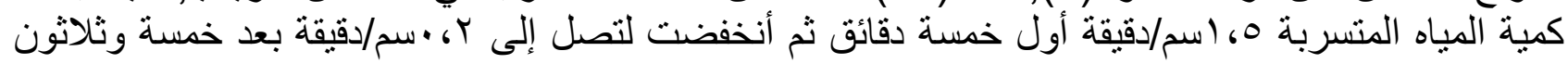
دقيقة من بدء التجربة.

جدول (V) معدل التسرب في الموقع الخامس في تربة رملية خشنة جنوب الطريق الدولي الساحلي

\begin{tabular}{|c|c|c|c|c|c|c|c|}
\hline ro & $\bar{\mu}$ r. & ro & r. & 10 & 1. & 0 & الزمن (دقيقة) \\
\hline $.6 Y$ & $.6 Y$ & .6 & .60 & .60 & $.6 \mathrm{~V}$ & 1,0 & معدل التسرب(سم/دقيقة) \\
\hline
\end{tabular}

المصدر: من حساب الطالبة اعتماداً على الدر اسة الميدانية

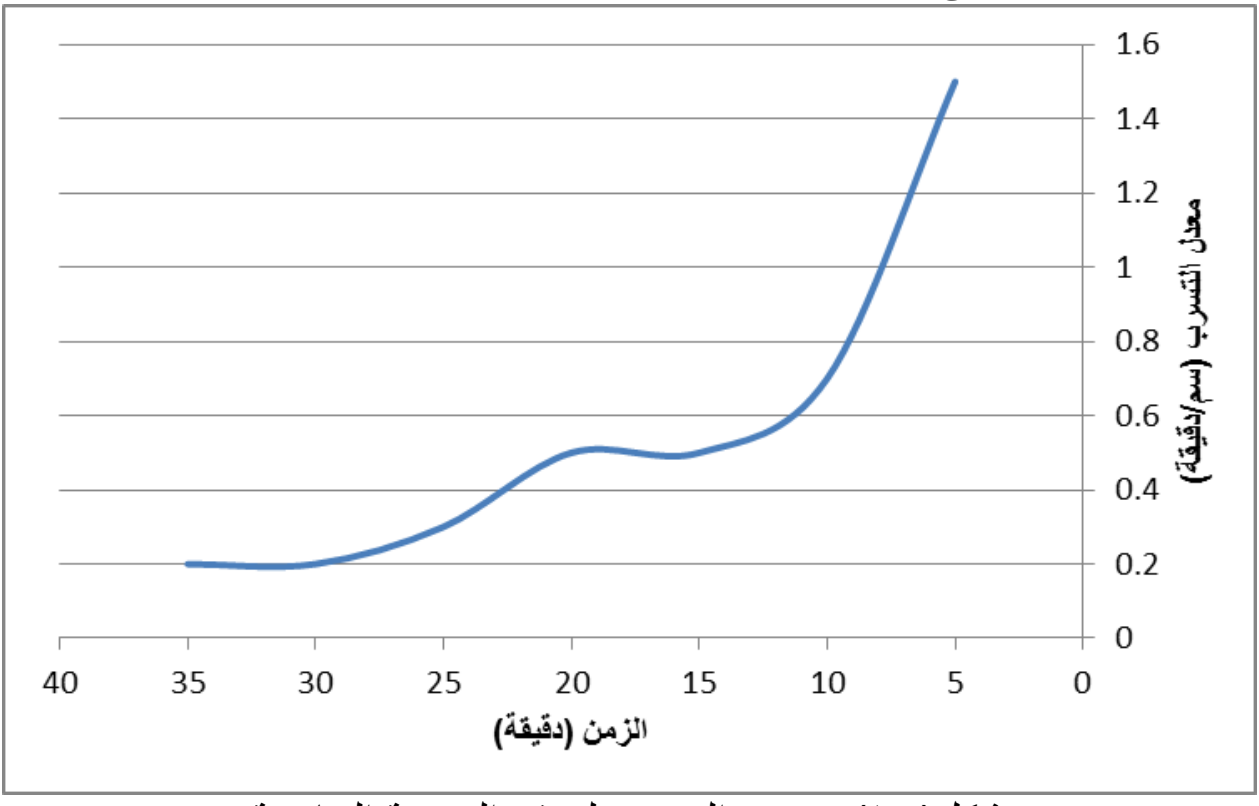

شكل( • ( ) منحنى التسرب لموقع التجربة الخامسة 
الموقع السادس: من دراسة جدول(^), وشكل(1 (1) نلاحظ ان معدلات التسرب بالتربة الملحية بمنطقة مصيف

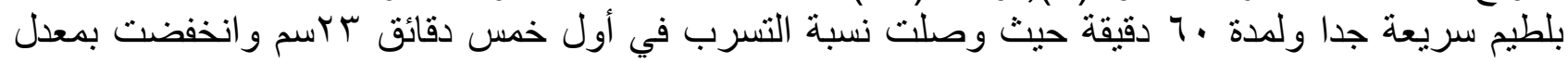
بسيط جدا حتى وصلت برسم حسم بعد خمسه وخمسون دقيقة.

جدول (^) معدل التسرب في الموقع السادس بالتربة الملحية بمنطقة مصيف بلطيم

\begin{tabular}{|c|c|c|c|c|c|c|c|c|c|c|c|c|}
\hline 7. & 00 & 0. & $\leqslant 0$ & $\varepsilon$. & ro & $r$. & ro & $r$. & 10 & 1. & 0 & الزمن (دقيقة) \\
\hline rt & rr & Tr. & YY. & Y Y 60 & Yr.T & YY.T & Yr.V & $r r_{6} q$ & rr.q & r & r & التسرب(سم/دقيقة) معدل) \\
\hline
\end{tabular}

المصدر: من حساب الطالبة اعتماداً على الدر اسة الميدانية

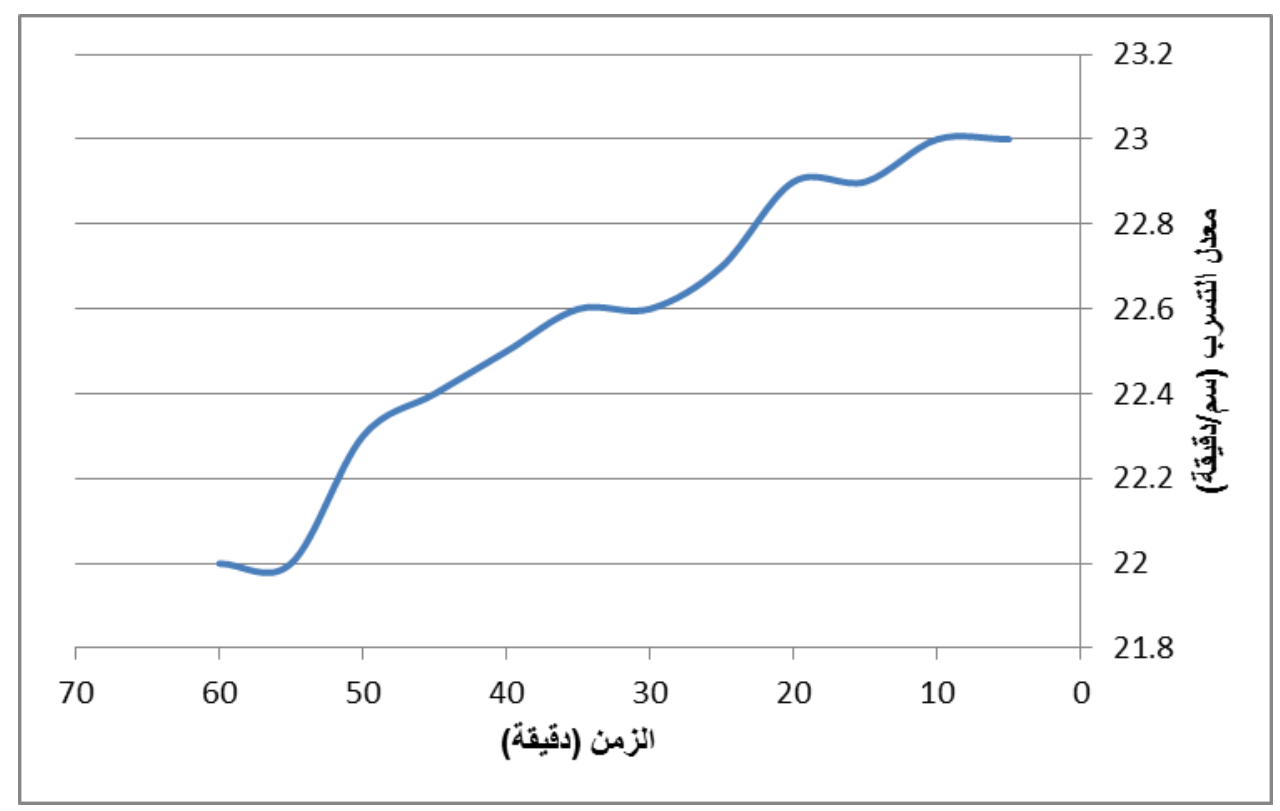

شكل(1 (1) منحنى التسرب لموقع التجربة السادسة

الموقع السابع: من در اسة جدول(9), وشكل (Y Y) نلاحظ أن معدل التسرب بتربة الكثبان الرملية بهذه المنطقة

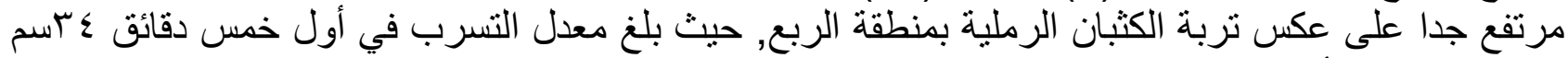
وهذا بعتبر ثاني أعلى نسبة تسرب بعد ثربة تربة الكثبان الرملية بمنطقة الثهابية.

جدول (9) معدل التسرب في الموقع السابع بتربة كثبان رملية بمدخل مصيف بلطيم

\begin{tabular}{|c|c|c|c|c|c|c|c|c|c|c|c|c|c|c|c|}
\hline 10 & $1 \leqslant$ & 14 & IT & 11 & 1. & 9 & $\Lambda$ & V & 7 & 0 & $\varepsilon$ & $r$ & $r$ & 1 & الزمن (دقيقة) \\
\hline$\varepsilon$ & $\varepsilon$ & $\varepsilon$ & 0 & 0 & 0 & 0 & 0 & 0 & 0 & 7 & 7 & V & $V$ & $\wedge$ & التسرب(سم/دقيقة) \\
\hline
\end{tabular}

المصدر: من حساب الطالبة اعتماداً على الدراسة الميدانية 


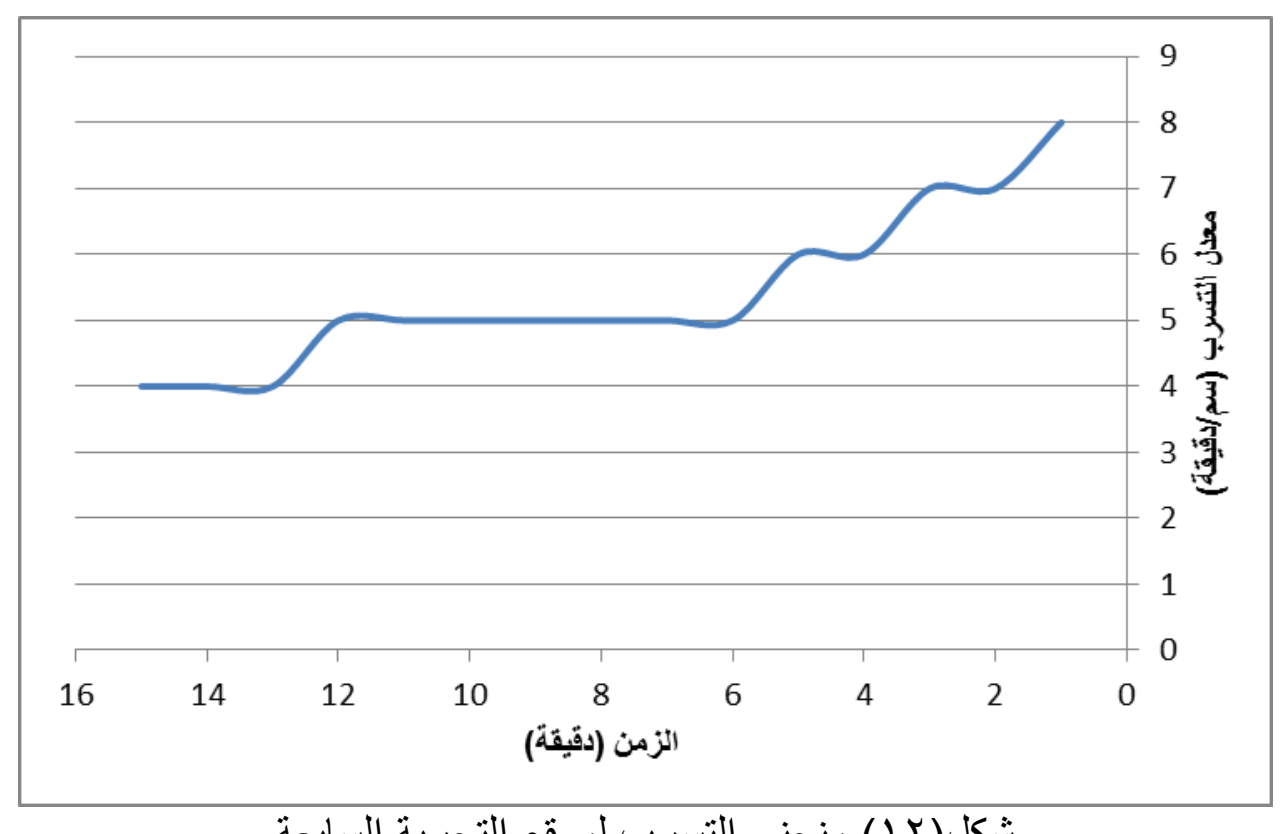

شكل(r ( ) منحنى التسرب لموقع التجربة السابعة

اعتماداً على نتائج التجربة الميدانية نستنتج ما يأتي:

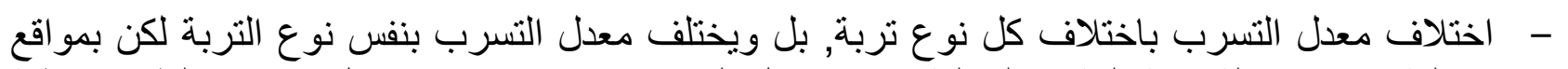

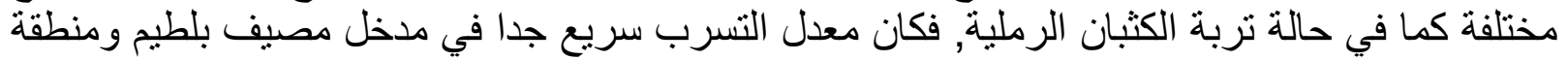

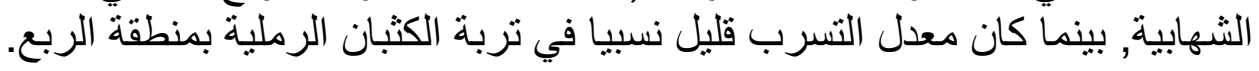

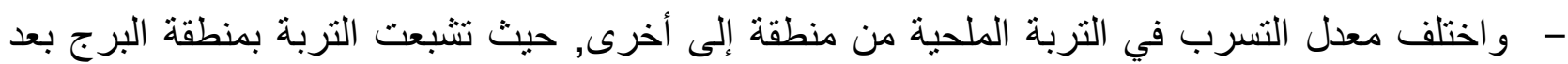

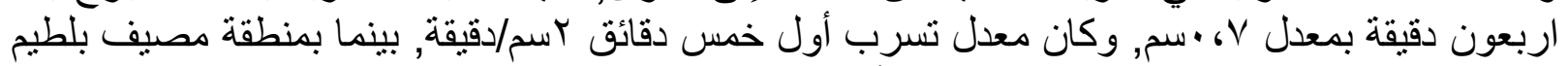

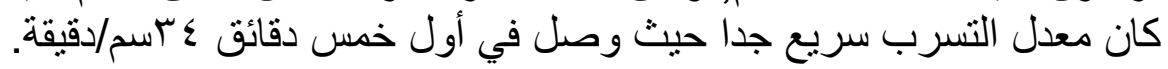

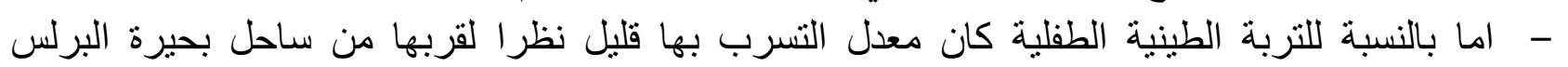
وتشبعها بمياه البحيرة. - ـ ـ وتثقارب كميات التسرب لكل من التربة الطينية الطفلية و التربة الرملية الخشنة في معدل التسرب القليل,

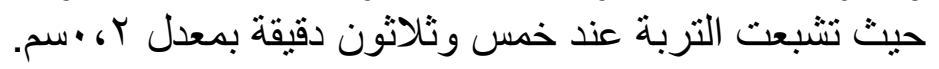

تتائج القياس الميدانى لعدد VI الموقع مياه:

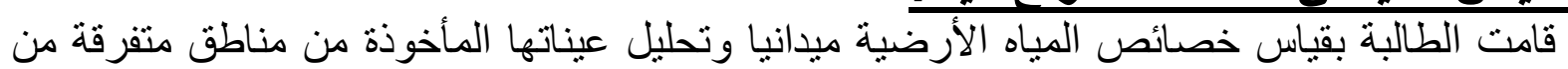

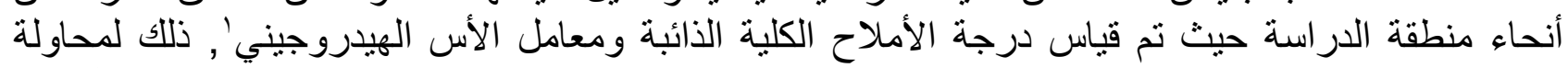

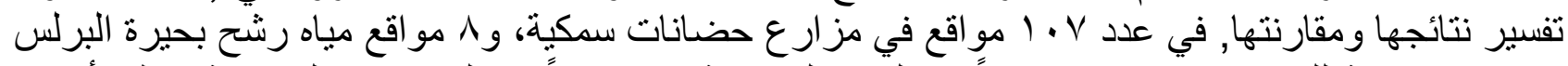

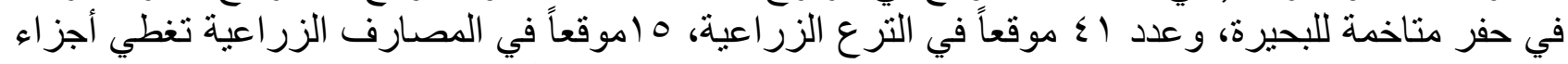

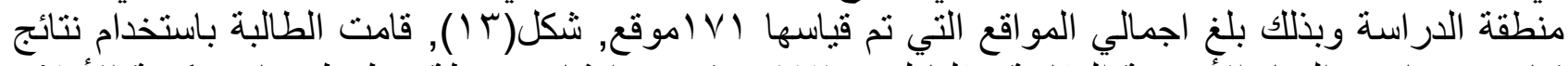

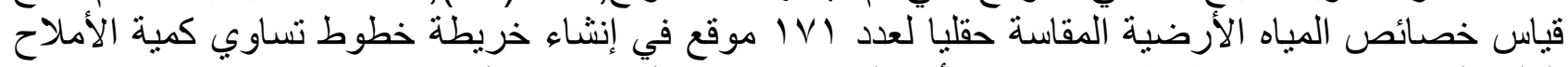

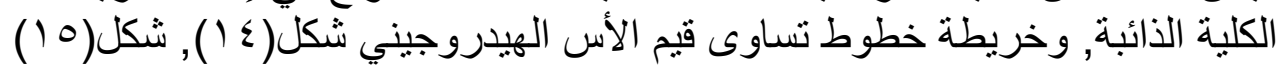




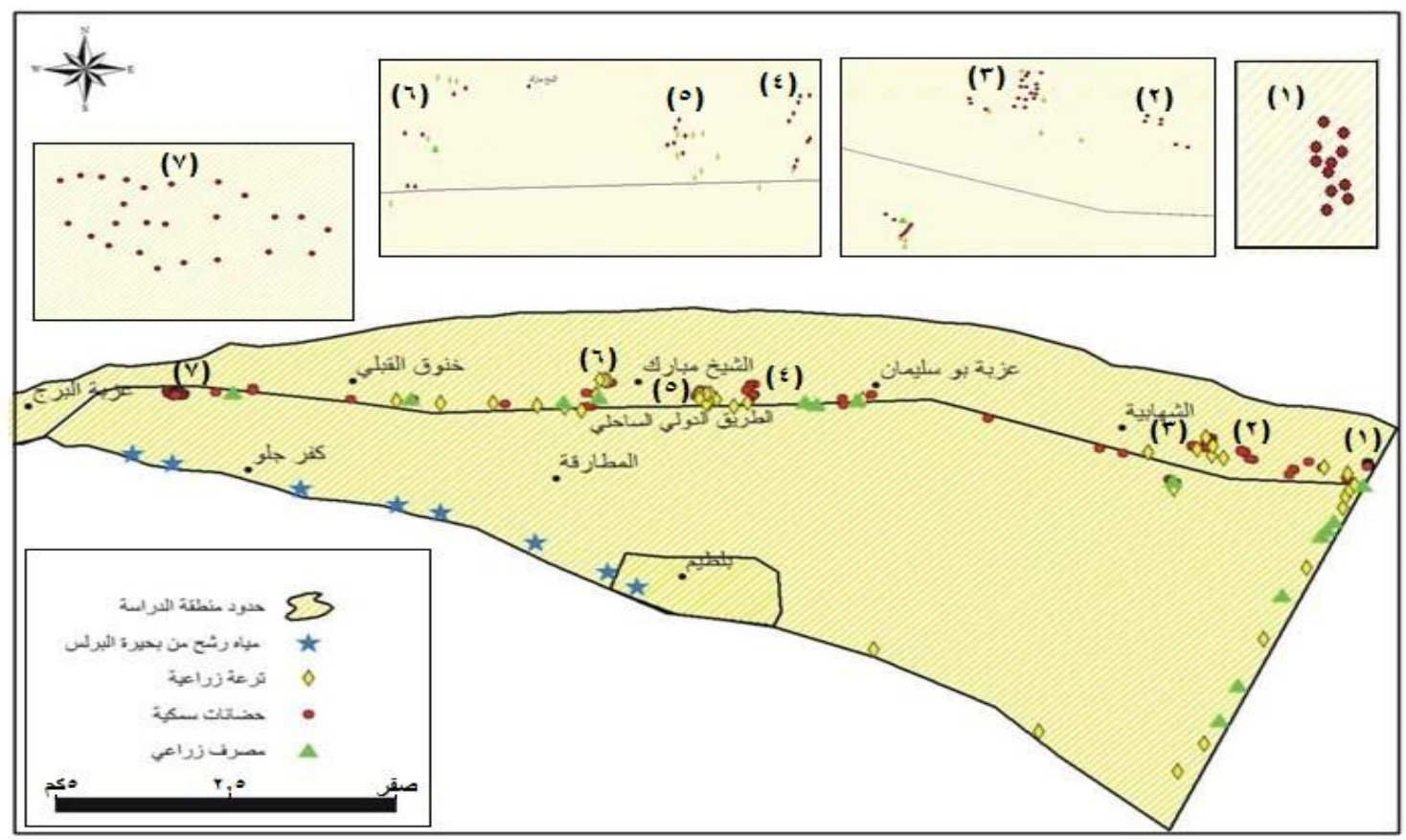

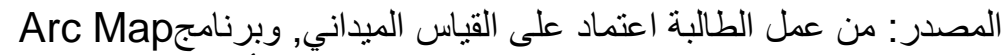

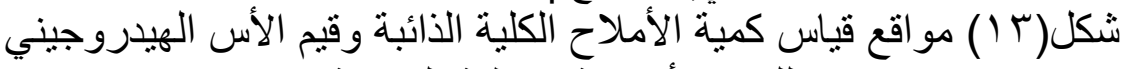

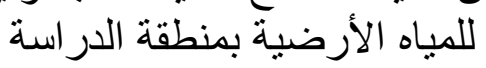

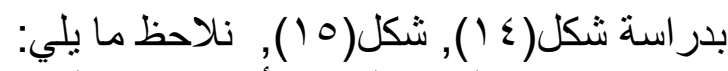

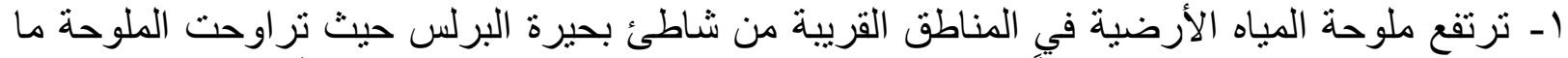

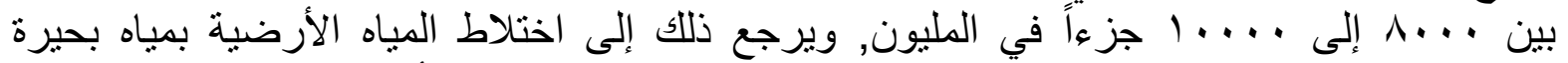
البرلس مرتفعة الملوحة, وتنخفض في بعض المصارف الزر اعية والتر الترع بأقصى شرق منطقة الدر اسة التهاه

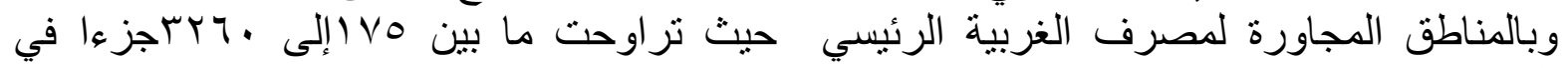

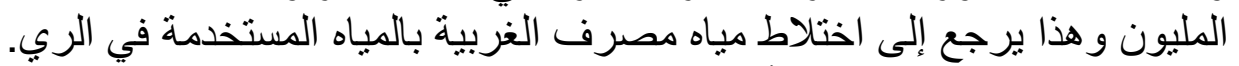

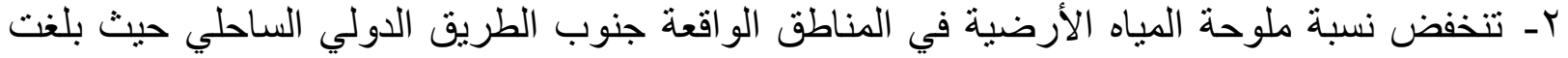

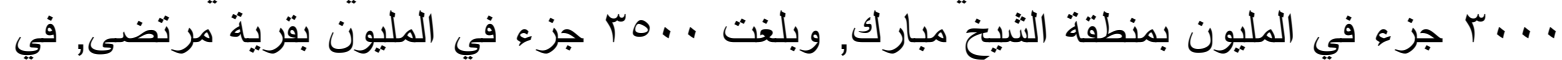

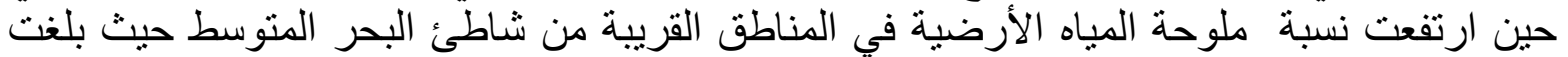

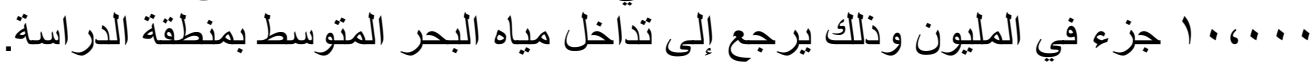

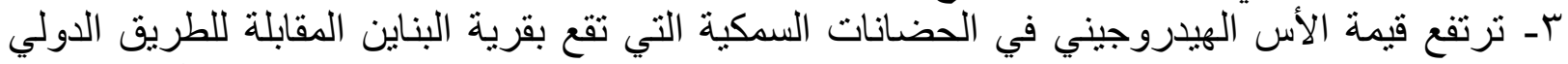

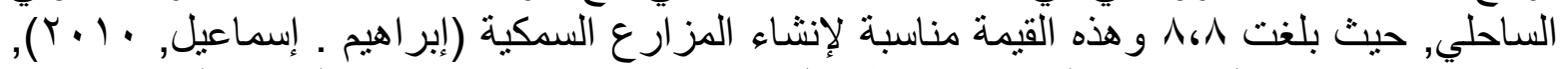

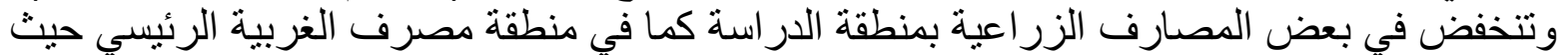



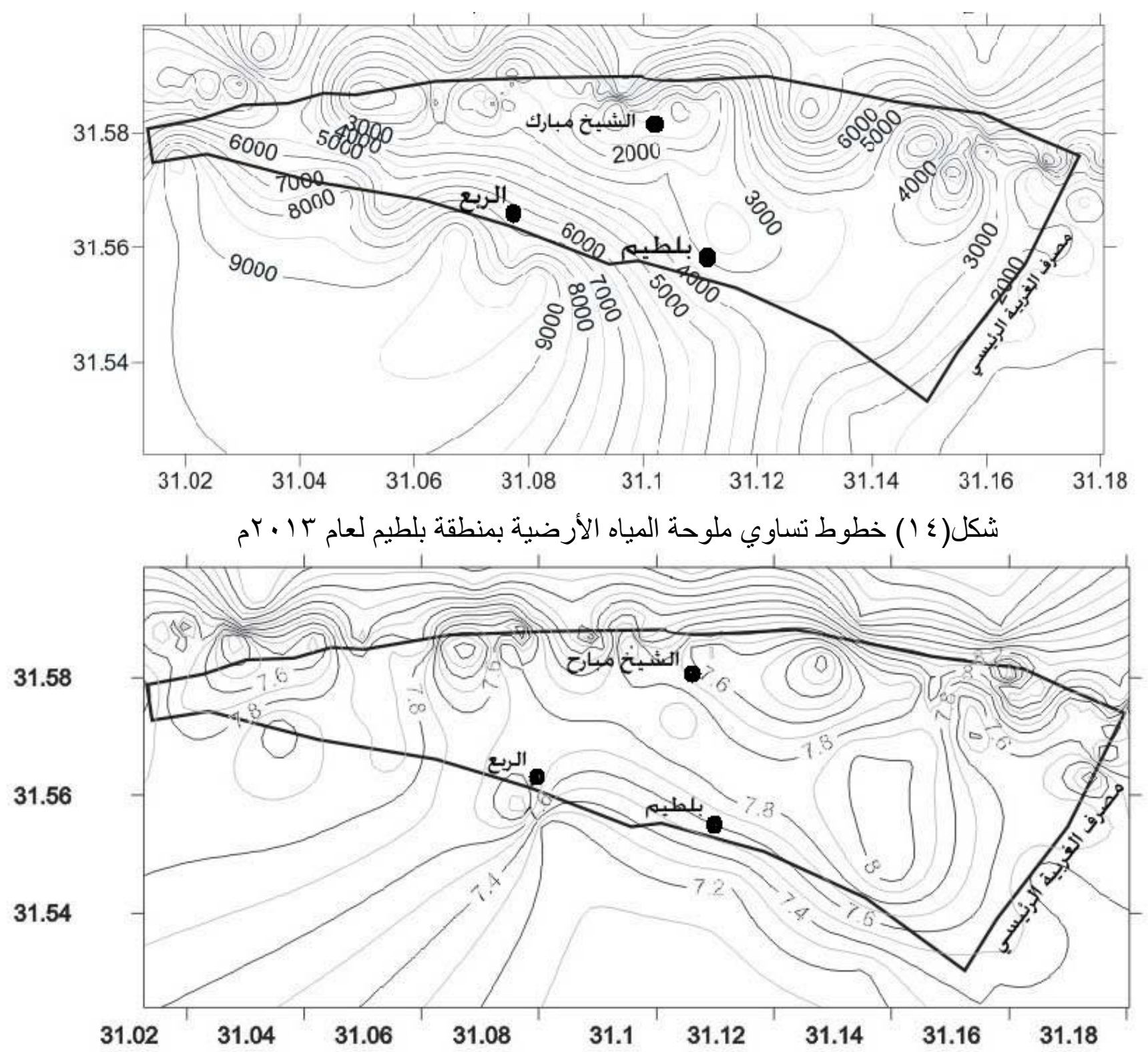

شكل(0 1) خطوط تساوي قيم الأس الهيدروجيني بمنطقة بلطيم لعام با ـ بام

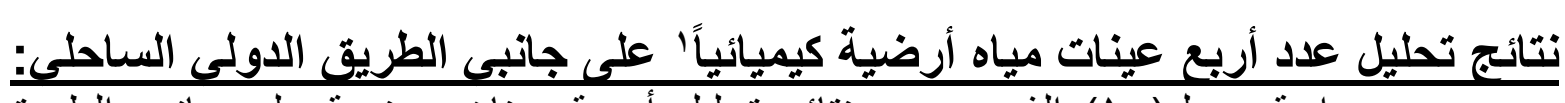

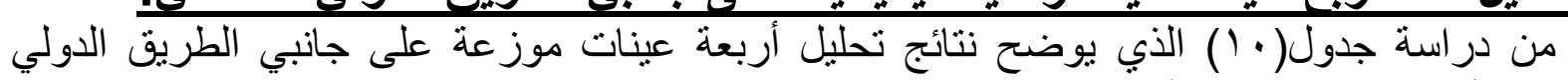

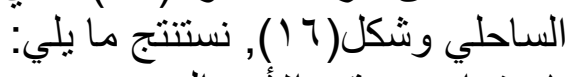

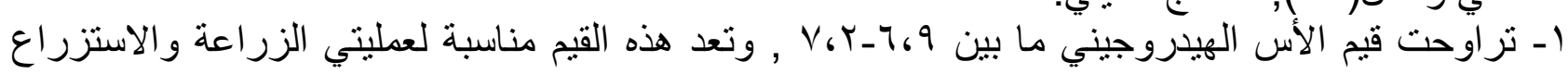

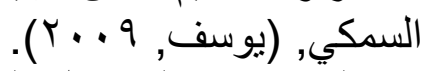

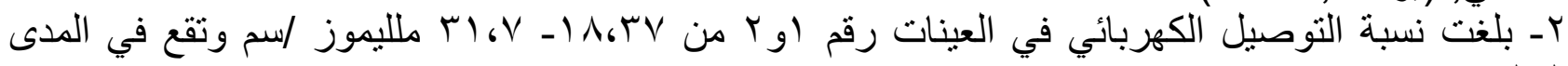

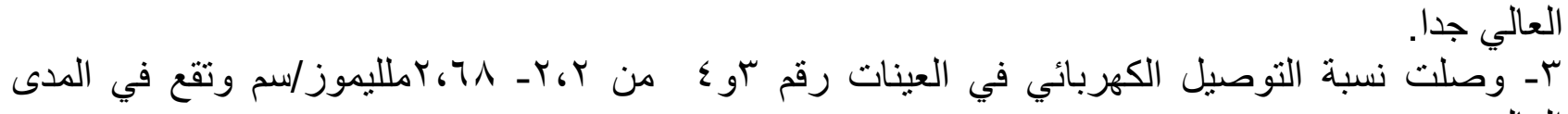
ــ العينات رقم او r مرتفعة الملوحة و لا تصلح للري نهائيا لأنها تتسبب في ذبول النباتات وموتها. 


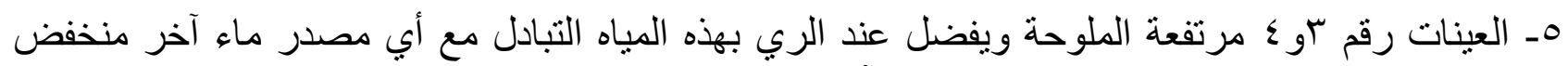

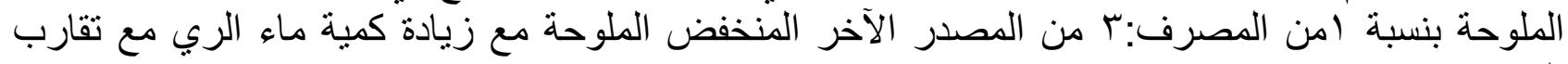

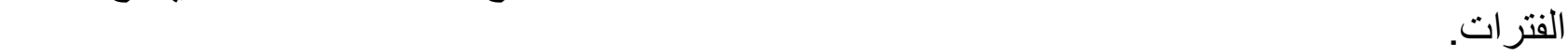

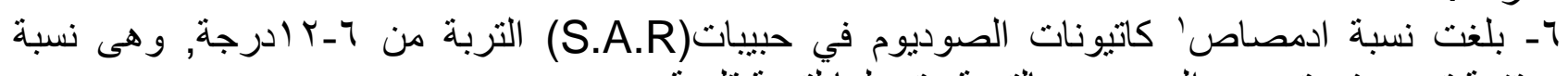

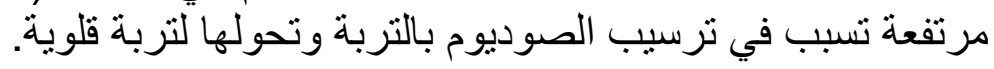

جدول( • () نتائج التحليل الكيمبائي لعينات المياه الأرضية

\begin{tabular}{|c|c|c|c|c|c|c|c|c|c|c|c|c|}
\hline \multirow{2}{*}{ S.A.R } & \multicolumn{4}{|c|}{ الانيونات (ملليمكافئ /لتر) } & \multicolumn{4}{|c|}{ الكاتيونات(ملليمكافئلتر) } & \multirow{2}{*}{ 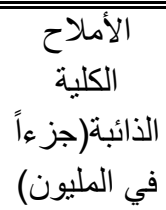 } & \multirow{2}{*}{ الكهربائيل } & \multirow{2}{*}{ الهيدروجيني } & \multirow{2}{*}{ 5 } \\
\hline & كبريتات & كلوريد & بيكربونات & كربونات & بوتاسيوم & صوديوم & ماغنيسيوم & 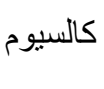 & & & & \\
\hline $\bar{v}$ & 97.6 & 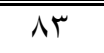 & $\overline{Y r V}$ & 1,4 & T,TH & 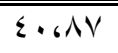 & $\sum 9,1$ & 9.61 & $V .0 \leqslant$ & $1 \Lambda^{\prime \prime}, \mathrm{rV}$ & 7.9 & 1 \\
\hline 7 & $1 \leq 0,7$ & $17 V$ & Y.9 & 1,0 & r.V9 & ¿V،乞l & $\overline{A N} V_{6} \mathrm{~T}$ & IVA, & IYIVY & TI.V & 7.1 & $r$ \\
\hline 11 & T.T & $1 V_{6} r$ & T.0 & - & .679 & $1 \varepsilon_{6} 11$ & T.V & $\varepsilon 60$ & $\Lambda \leqslant \varepsilon$ & $\overline{Y G}$ & 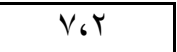 & $r$ \\
\hline IT & 1,1 & $r_{6} \wedge$ & Y. 9 & - & .671 & $1 V_{6} T_{9}$ & r.9 & 0,9 & $170 \leqslant$ & r.71 & V & $\varepsilon$ \\
\hline
\end{tabular}

المصدر: تحليل العينات بمعمل خصوبة التربة بمديرية الزراعة بالبحيرة

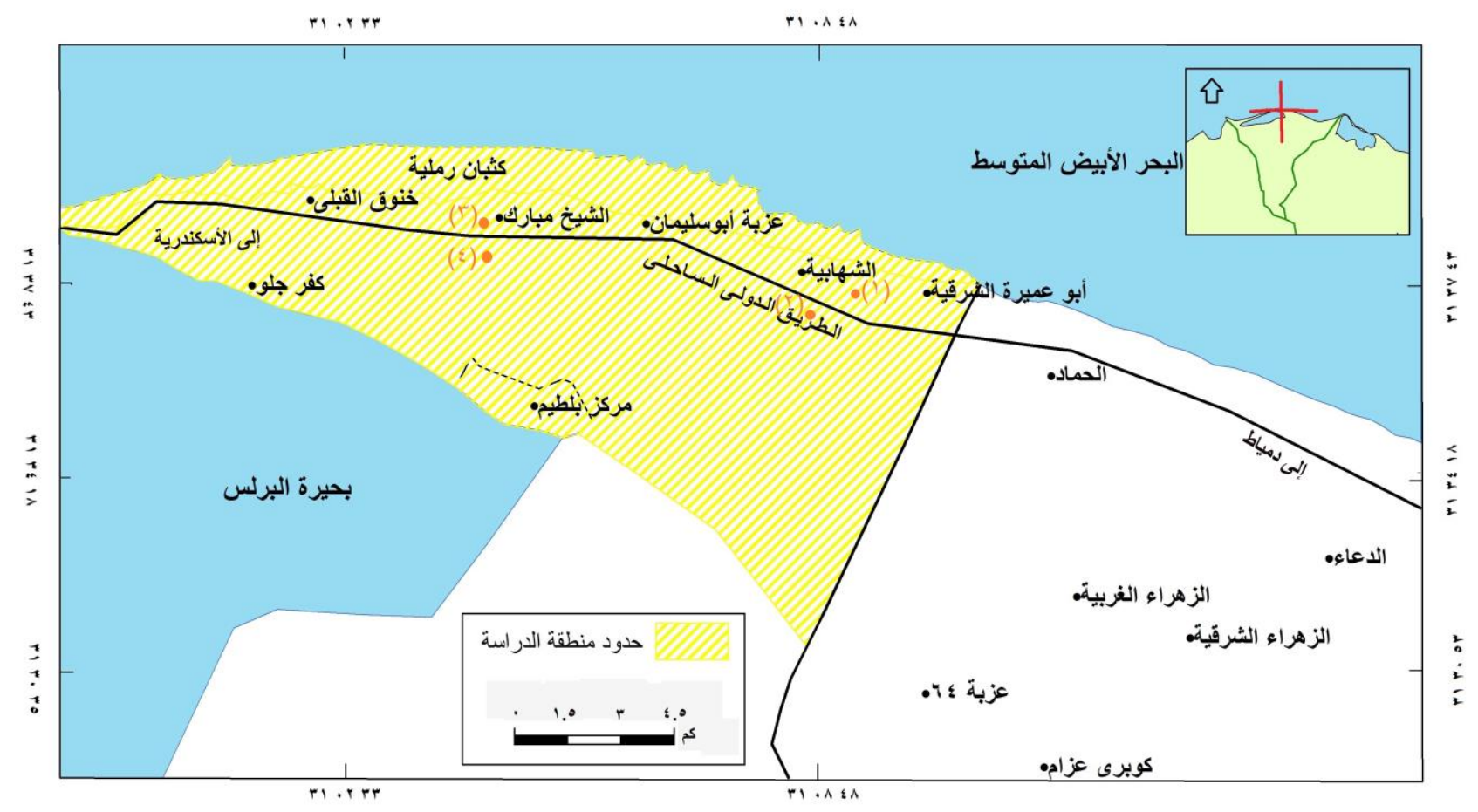

شكل(7 1 ) مو اقع تجميع عينات المياه الأرضية بمنطقة الدر اسة

' هنالك فرق بين مصطلح إدمصاص وامتصاص, كلمة إدمصاص تعني تركز المادة على سطح التربة , كلمة امتصاص تعني هو انتقال المياه من الوسط

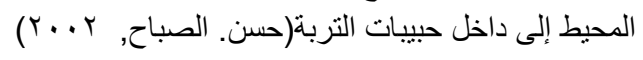




\section{نتائج تحليلات عينات التربة كيميائياً' بمنطقة الدراسة:}

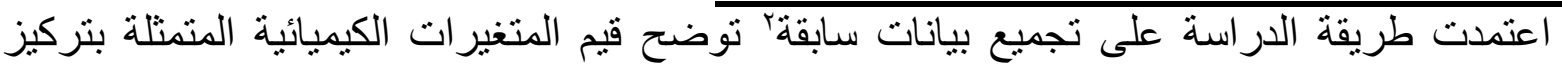

الايونات الموجبة(البوتاسيوم

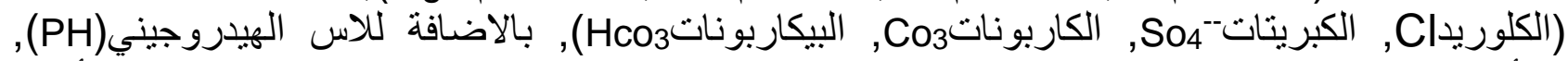

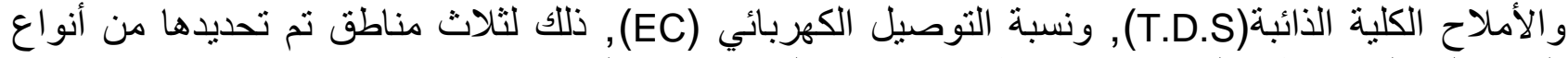

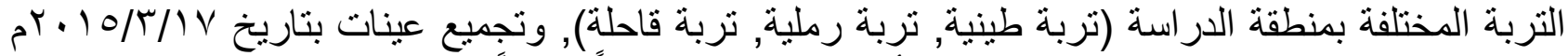

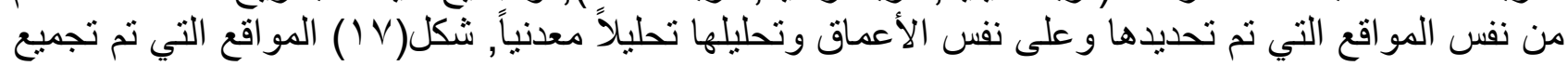
عينات تربة منها:

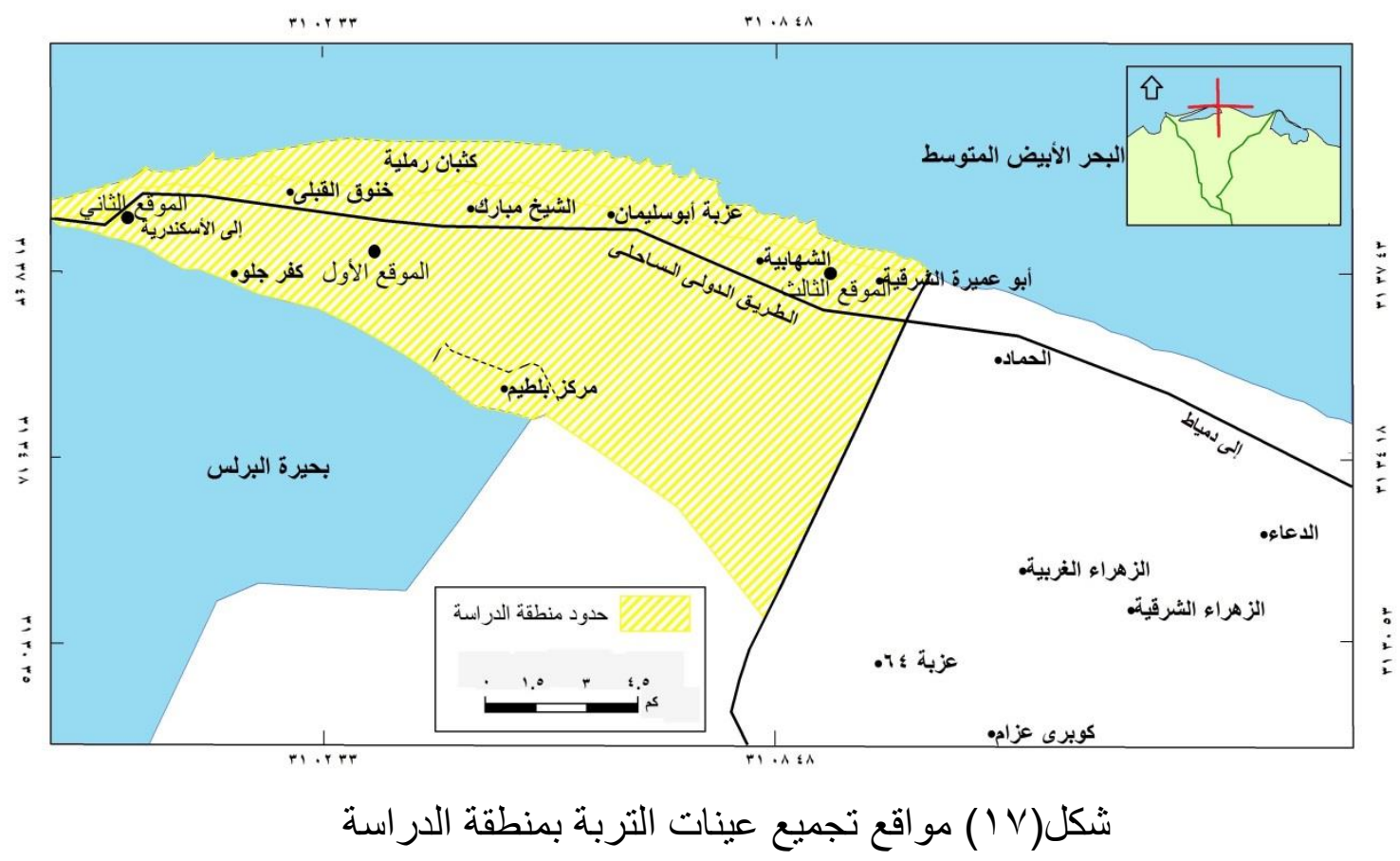

ا نم تحليلها بجامعة الاسكندرية كلية الزراعة وحدة التحاليل والخدمات العلمية نشاط الأراضي والمياه للمعلومات والخدمات والتدريب

Effect of irrigation, nitrogen and organic fertilization on soil water relationships of اعتمدت الطالبة على بيانات نعالج موضوع Osman, ) في منطقة الربع, وموضوع Studies on salt affected soils (Abdel-Hafez, et al., 2008) إعداد zea maize crop Sorption of sulphate in alkaline soils as affected by wetting and drying processes

1987) بمنطقة البرلس, وموضوع إعداد(Shams, et al., 2001), لتربة الأراضي الرملية 
أـ نتائج تحليل عينات التربة بمنطقة الربع:

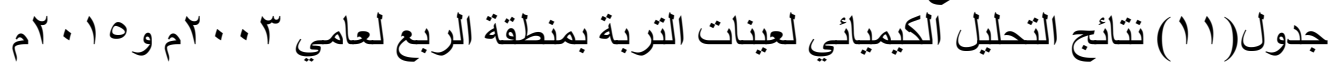

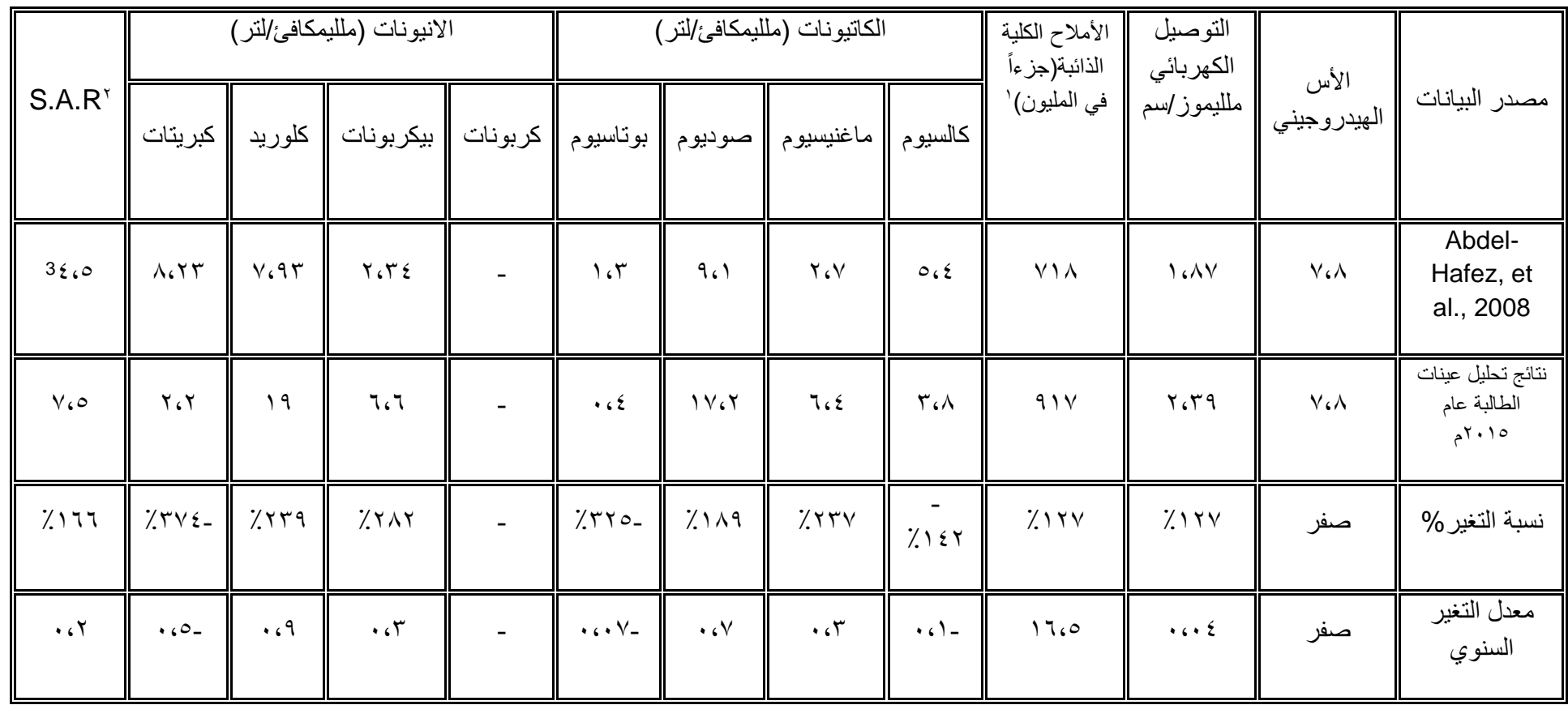

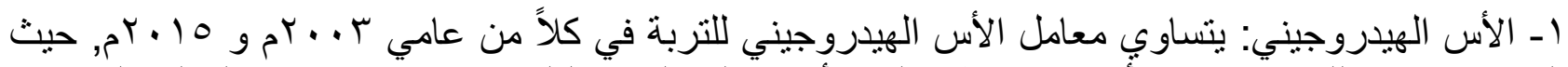

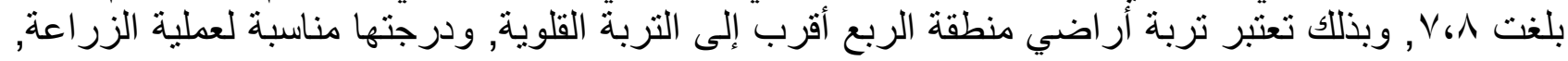

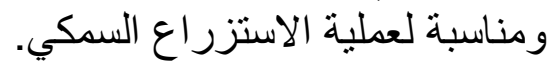

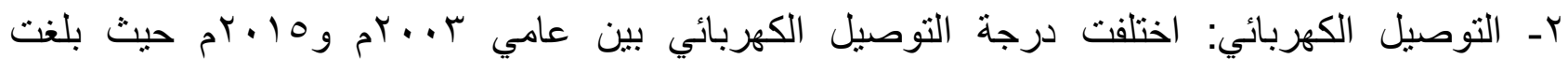

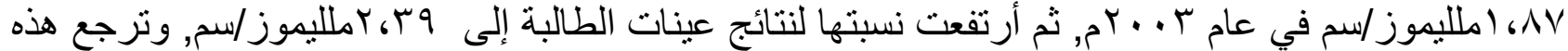
الزيادة إلى ارتفاع درجات الحرارة مما أدي إلى زيادة نسبة التبخر وتركز الأملاح في التربة, وتعتبر نتائج

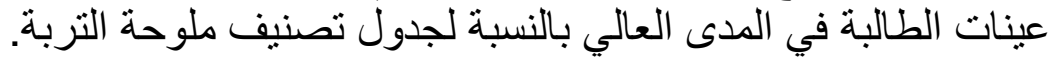

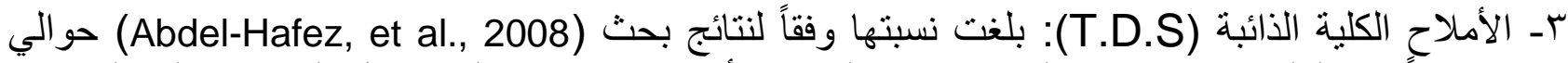
AاV جزءأ في المليون, وتعد هذه النسبة مناسبة لزراعة أنواع عديدة من المحاصيل الزراعية المختلفة منها

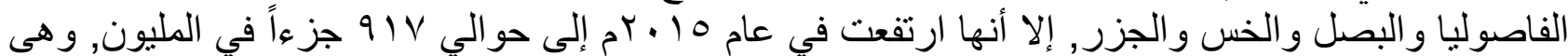
تناسب زر اعة محاصيل الطماطم و الخيار و البطاطس. عـ الكاتيونات: وتثمثل في الكالسيوم والماغنسيوم والصوديوم و البوتاسيوم, وهي من العناصر الغذائية التي

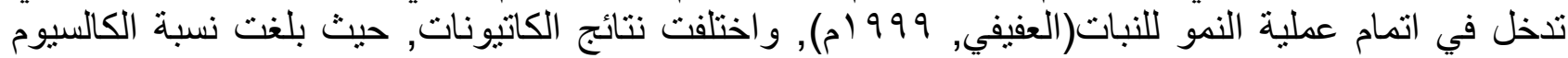

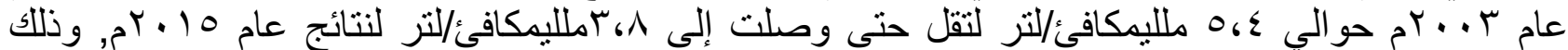

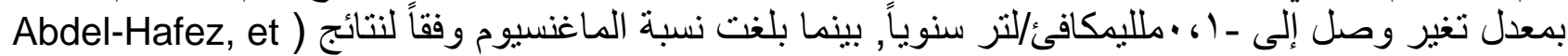

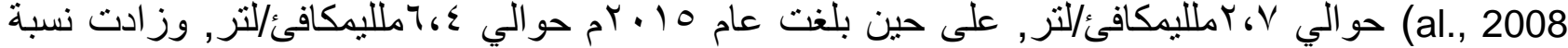

' من حساب الطالبة باستخدام المعادلة الأتية:T.D.S= EC*0, 6 *640, هي نسبة التوصيل الكهربائي, T.D.S: هى نسبة الأملاح الكلية الذائبة

S.A.R ' هي درجة ادمصاص كاتيونات الصوديوم في حبيبات التربة

† حساب S.A.R من حساب الطالبة اعتماداً على المعادلة الأتية: S.A.R = Na/V(Ca + Mg)/2 (العفيفي, 1999) ) 
الصوديوم خلال الفترة الزمنية للار اسة بحو الي V، •ملليمكافئ/لتر سنوياً, وانخفض عنصر البوتاسيوم بنسبة ـ

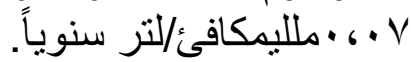

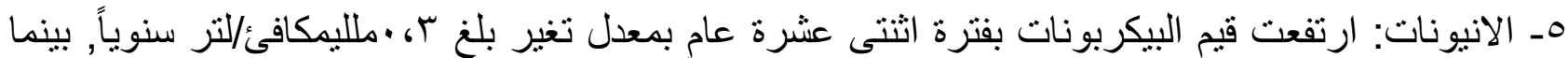

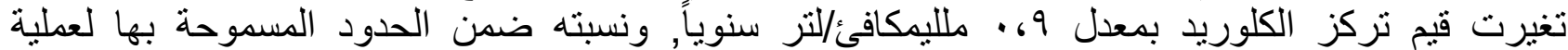
الزر اعة, بينما انخفضت قيم تركز الكبريتات بمعدل تغير ـ0، • ملليمكافئلثنز سنوياً.

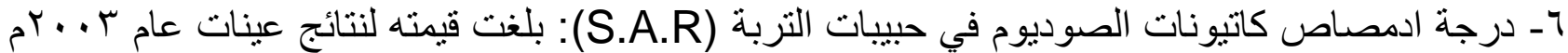

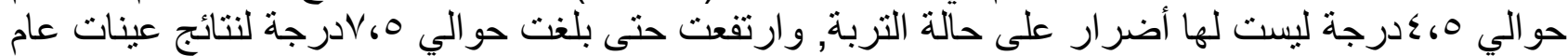

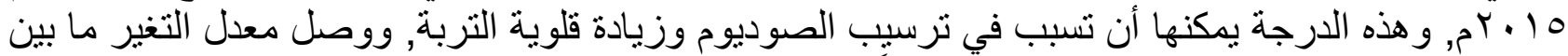

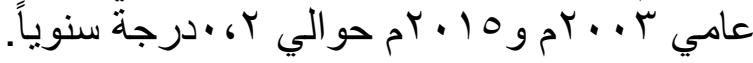
بـ نتائج تحليل عينات التربة بمنطقة البرلس:

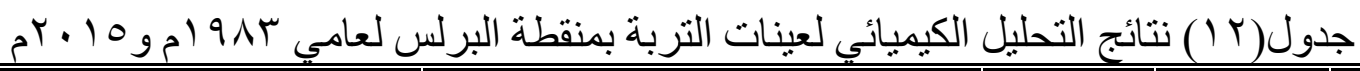

\begin{tabular}{|c|c|c|c|c|c|c|c|c|c|c|c|c|c|}
\hline \multirow{2}{*}{ 妾 } & \multicolumn{4}{|c|}{ الانيونات (ملليمكافئ/لتر) } & \multicolumn{4}{|c|}{ الكاتيونات (ملليمكافئلتز) } & \multirow{2}{*}{ 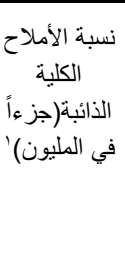 } & \multirow{2}{*}{ ملالكهربانئي } & \multirow{2}{*}{ الهيلروجيني } & \multirow{2}{*}{ سم } & \multirow{2}{*}{ 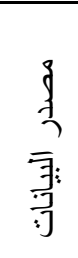 } \\
\hline & 年. & $\begin{array}{l}y \\
7 \\
7\end{array}$ & 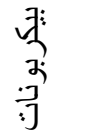 & 泉 & 亲 & $\begin{array}{l}\frac{3}{3} \\
\frac{3}{2} \\
2\end{array}$ & 童 & $\underset{3}{3}$ & & & & & \\
\hline 111.7 & (1.5 & 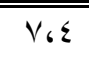 & $T_{\text {r. }}$ & - & $.6 r$ & $1 \cdot 64$ & $.6 r$ & .64 & 1.7 & T.1 & $\wedge$ & سطحية & $\frac{1}{3}$ \\
\hline $1 \cdot 6 V$ & .67 & 961 & $.6 \wedge$ & - & . & $96 \varepsilon$ & .60 & .69 & VYq & 1.9 & $V_{6} \wedge$ & $\overline{~ r .}$ & 5 \\
\hline 10 & $V_{6} V$ & r r.o & 161 & - & • & rצ.7 & r & $\varepsilon_{6}{ }^{\top}$ & 1997 & $0, r$ & $V_{6} V$ & 7. & ల్ల్ \\
\hline $1 T 6 V$ & $\varepsilon_{6} \wedge$ & r & $V_{6} 7$ & أثنار & .60 & ro,V & $96 \varepsilon$ & $\varepsilon$ & 1701 & $\varepsilon, r$ & $\Lambda_{6} \vee$ & سطحية & \\
\hline $1 T_{G}$ & 1.0 & $T V$ & $V_{6} \varepsilon$ & أثثار & T. & $T V_{6} T$ & 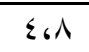 & r.7 & $110 r$ & $\Gamma$ & $A_{G} r$ & $r$. & \\
\hline 10,5 & $r$ & YT & $7, \varepsilon$ & أثثار & .65 & $T V_{6} r$ & $0, r$ & 1.7 & 15.0 & $r_{6} \varepsilon$ & $\left.\Lambda_{6}\right)$ & 7. & $\overline{3}$ \\
\hline 1 To_ & $17 \ldots$ & $\sum \wedge T$ & 417 & أثنار & 177 & ro. & $\varepsilon \vee \cdots$ & TrTH & $r \cdot \varepsilon$ & $r \cdot \varepsilon$ & 1.1 & سطحية & \\
\hline IYE & ro. & r97 & 9 9Yo & أثنار & صفر & r^q & 97. & $\varepsilon \ldots$ & $10 \mathrm{~V}$ & $10 \mathrm{~V}$ & 90 & r. & 7 \\
\hline 1.1 & rNo_ & 110 & roo & أنثار & (T- & $1 . r$ & r.. & rTA- & 10Y & 10Y- & 1.0 & 7. & ১0 \\
\hline $.610_{-}$ & $.61 \leqslant$ & .619 & .617 & أنثار & .67 & $.6 \vee 9$ &. . YA & .611 & YY، & .6 .7 & $.6 \cdot Y$ & سطحية & 3 \\
\hline$\cdot 6 \cdot 1$ &..$\cdot Y$ & .000 & $.6 r$. & أثنار & صفر & .000 & $.61 \pi$ &.$\cdots 1$ & $1 T_{6}$ & . & 9.61 & r. & $q$ \\
\hline ב... & $.61 V_{-}$ & .61 & . . II & أثنار & 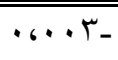 & $\overline{.6 \cdot r}$ & .61 & 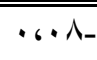 & Y1.0. & 9.0. & $.61 Y$ & 7. & 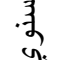 \\
\hline
\end{tabular}

' من حساب الطالبة باستخدام المعادلة الأتية:640 


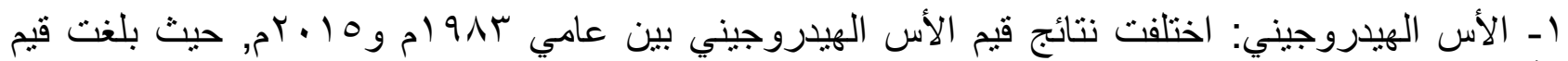

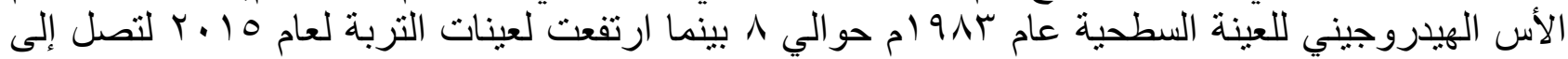

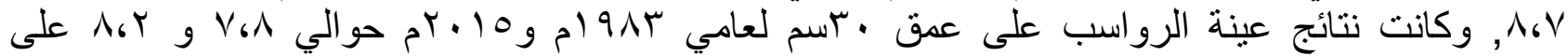

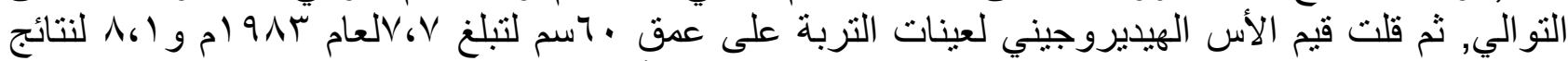

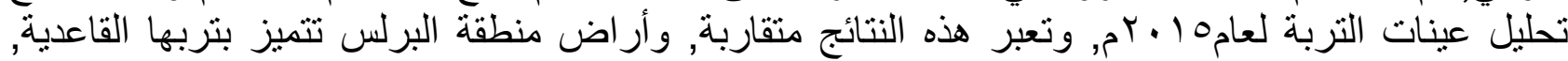

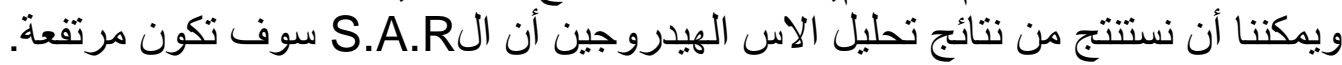

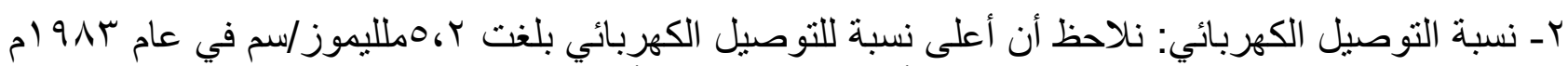

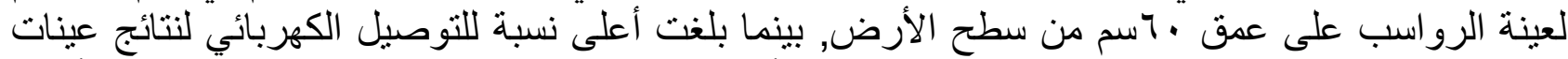

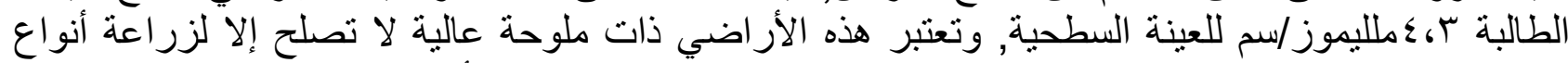

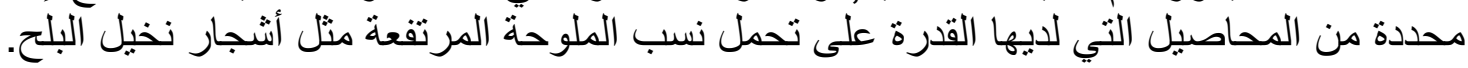

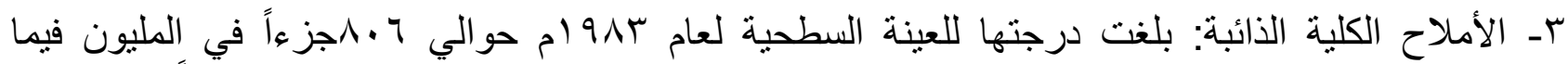

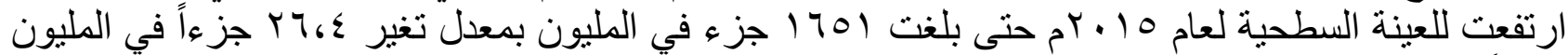

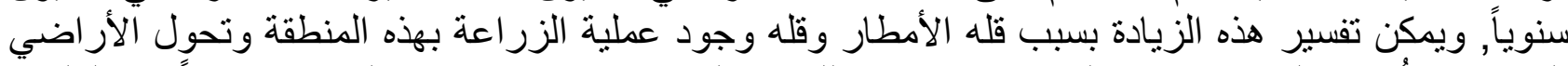

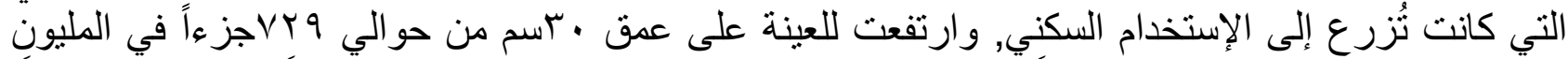

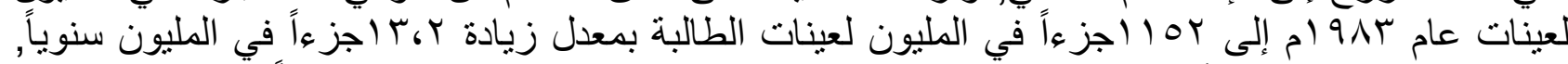

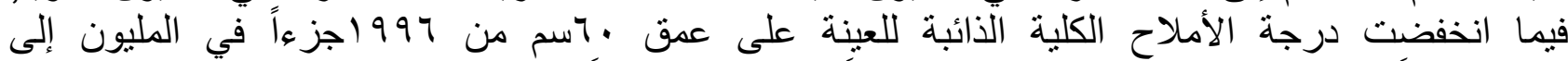

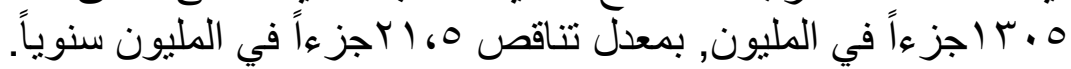

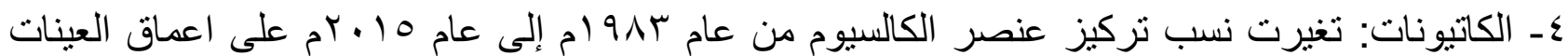

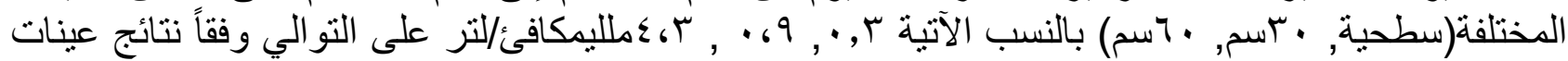

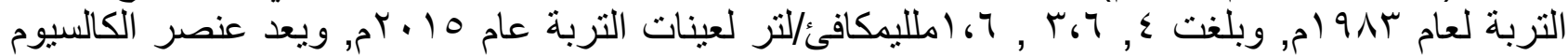

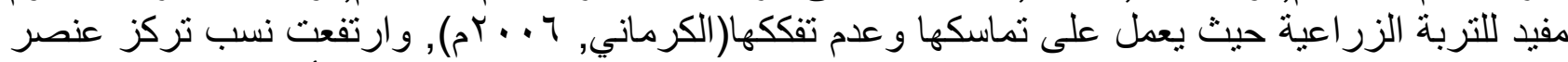

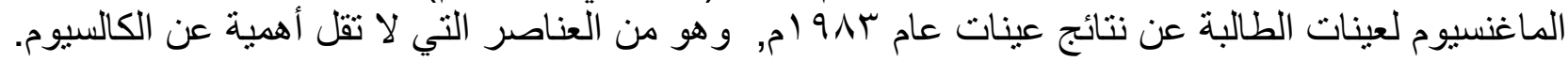

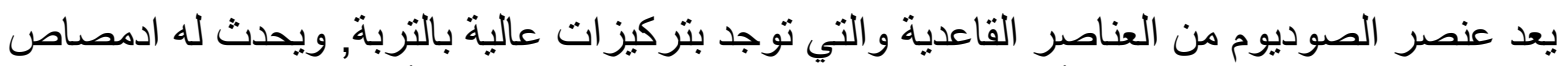

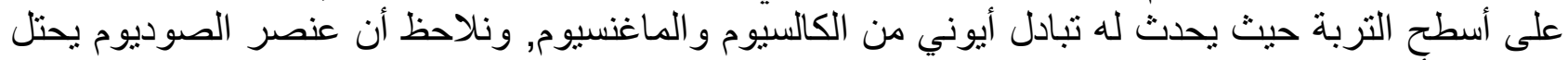

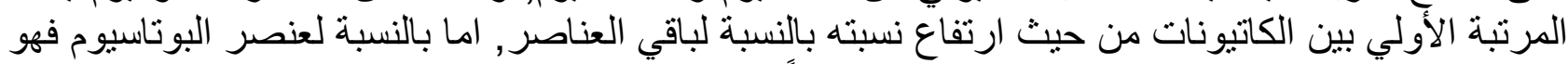

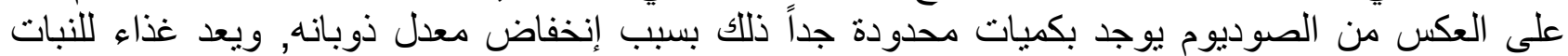

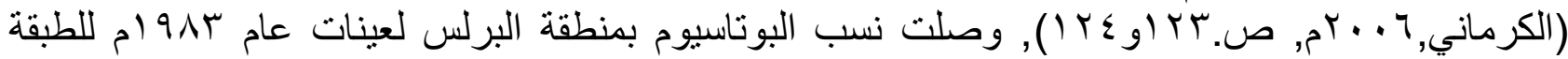

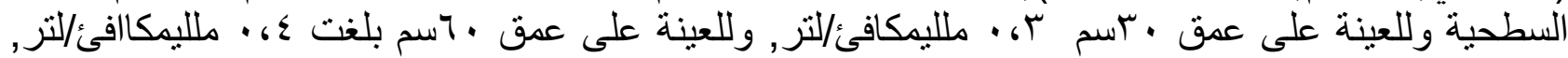

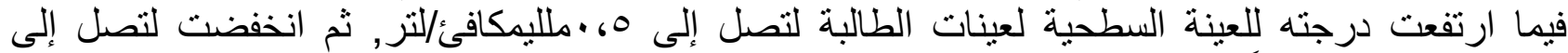

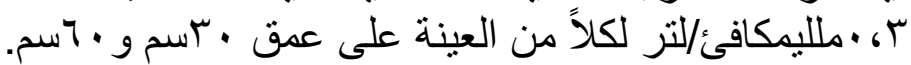

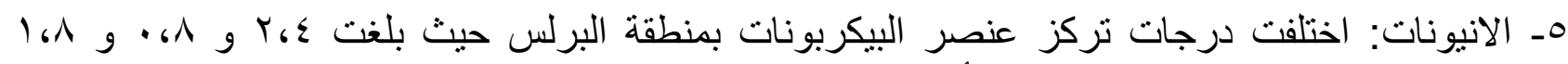

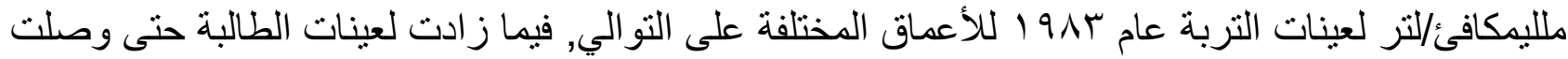

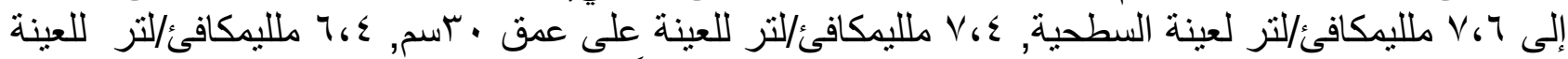

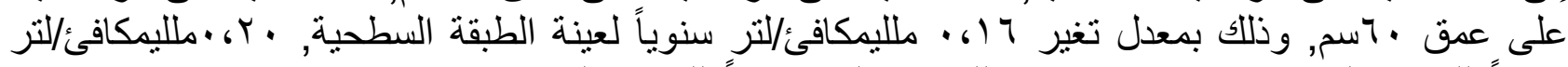

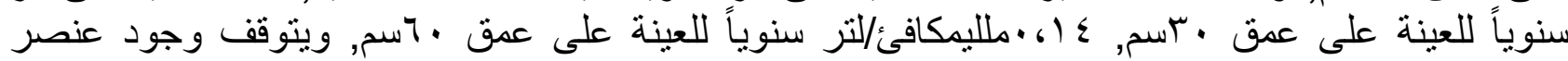
الييكربونات تتوقف على الأس الهيدروجيني.

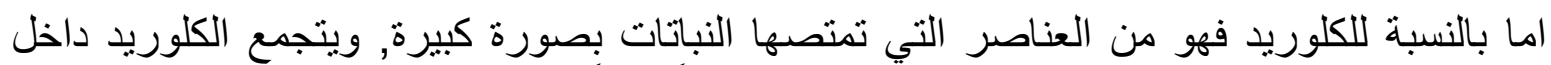

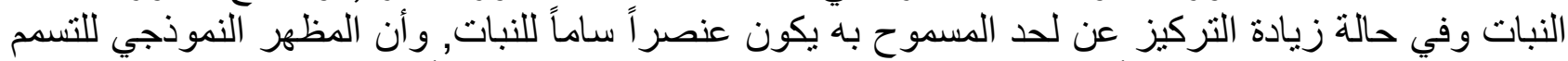

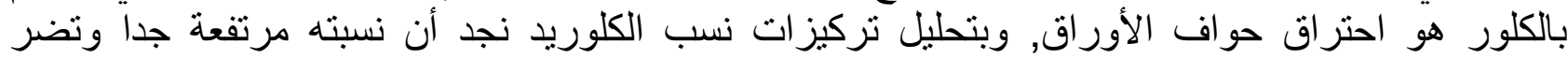

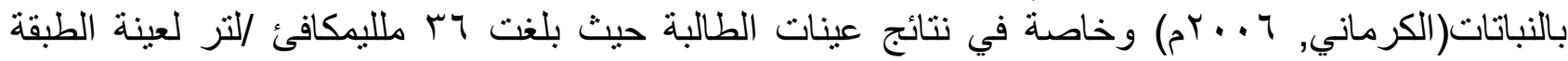

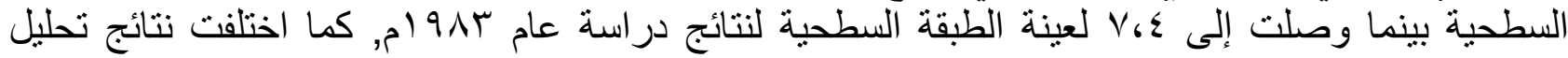


عنصر الكبريتات بين عامي الدر اسة, حيث انخفضت درجته للعينات السطحية وعلى عمق • اسم حبث بلغت

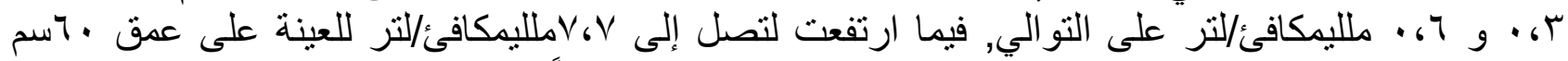

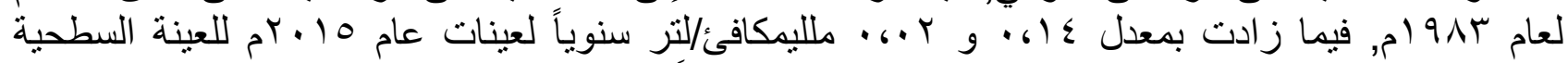

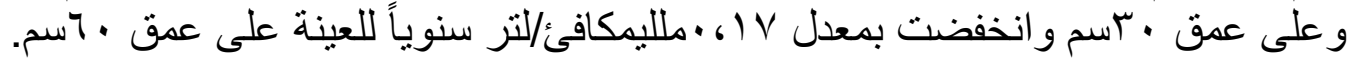

جـ نتائج تحليل عينات التربة بمنطقة الثهابية: ولتئ

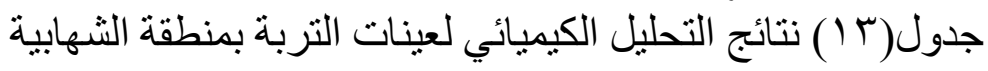

\begin{tabular}{|c|c|c|c|c|c|c|c|c|c|c|c|c|c|}
\hline \multirow{2}{*}{ ஸ } & \multicolumn{4}{|c|}{ الانيونات (ملليمكافئ/لتر) } & \multicolumn{4}{|c|}{ الكاتيونات (ملاليمكافئ/لتر) } & \multirow{2}{*}{ 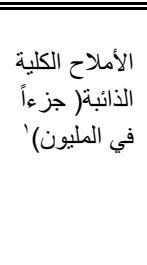 } & \multirow{2}{*}{ مالكهربائي } & \multirow{2}{*}{ الهياروجيني } & \multirow{2}{*}{ سم } & \multirow{2}{*}{ 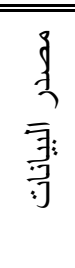 } \\
\hline & 年. & y & 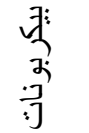 & $\begin{array}{l}3 \\
3 \\
3 \\
3 \\
3\end{array}$ & 榇 & $\begin{array}{c}2 \\
2 \\
\vdots \\
2\end{array}$ & 变: & 亲 & & & & & \\
\hline $1 \leq 6 V$ & rr,o & - & $\varepsilon r$ & - & $\left.r_{6}\right)$ & $\left.\leq \wedge_{6}\right)$ & $\varepsilon, r$ & IVGr & TYTY & 7.0 & $\left.\lambda_{6}\right)$ & سطحية & \\
\hline$M T^{2}$ & Tr & - & $\varepsilon$. & - & $\bar{r}$ & $\sum 1.9$ & 0.7 & 10,9 & $r \leqslant O V$ & 7 & $\overline{A, r}$ & r. & 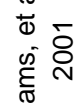 \\
\hline 11,0 & $r \leqslant 60$ & - & $\leqslant 7$ & - & $1 ، \varepsilon$ & $00, \mathrm{~V}$ & 0 & 14.9 & YATY & V & $\left.\lambda_{6}\right)$ & 7. & \\
\hline$r$ & 161 & $\varepsilon$ & r.7 & أثنار & $.6 r$ & $r .9$ & $1 ، \varepsilon$ & r.r & $r \leqslant 0$ & .67 & $\wedge$ & سطحية & $\mathrm{T}$ \\
\hline$\varepsilon, 0$ & $.6 r$ & 0 & $r_{6} \varepsilon$ & أثنار & $.6 r$ & $0, \varepsilon$ & .67 & T.r & rᄉT & $.6 \mathrm{~V}$ & 1,7 & $r$. & \\
\hline 7.7 & .69 & 7.5 & T، & أثنار & .65 & 7.9 & 1,4 & 1 & TrV &.$، 1$ & $\lambda_{6} \mathrm{~V}$ & 7. & 青 \\
\hline$\varepsilon 99$. & TIrצ_ & $\varepsilon \ldots$ & 1710 & أثنار & 1.0 .1 & ITrK- & "r... & VAI- & 1.人r- & $\overline{~ 1 . \wedge r_{-}}$ & 1.1. & سطحية & \\
\hline YAY- & $110 \ldots$ & $0 .$. & 1774 & أثنار & $1 \ldots$ & vvo- & qTr. & VTY- & $10 \mathrm{~V}_{-}$ & Nov- & $1 \cdot \varepsilon$ & $r$. & 7 \\
\hline YA.- & TVYY- & $\pi T$. & ITOY. & أثنار & va- & $\lambda \cdot V_{-}$ & ६17- & $1 \times 9 .-$ & AVO- & NVO- & $1 . V$ & 7. & $0^{\circ}$ \\
\hline •،৯ঙ- & $1.7-$ & . GSA & r.八- & أثار & $.61 \%$ & r.l- & $\cdot, r_{-}$ & $1-$ & IVYGT- & . ، $\leqslant Y_{-}$ & $\cdots V_{-}$ & سطحية & 3 \\
\hline $.60 \Lambda_{-}$ & 1.7 & . & r. T_ & أثنار & $.61 Y_{-}$ & T.7. & ב & $.69 V_{-}$ & 100 & . $6 T^{\prime} V_{-}$ & ... & $r$. & 哥。 \\
\hline • ‘ & $1,7 \Lambda_{-}$ & . $6 \leqslant \varepsilon$ & r. & أثنار & $\cdots \cdot \Lambda_{-}$ & 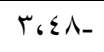 & . TY & . $110_{-}$ & $|\wedge| ، \varepsilon-$ & - & 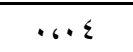 & 7. & 3 \\
\hline
\end{tabular}

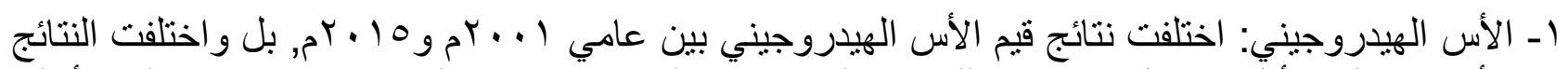

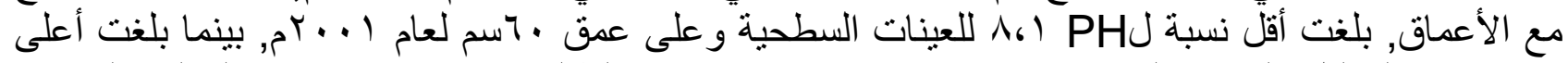

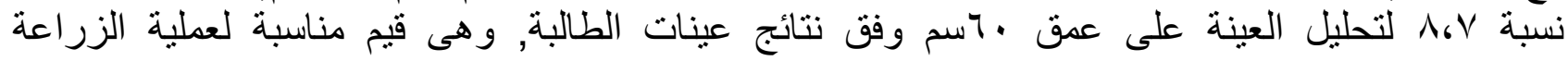
والاستزر اع السمكي. 


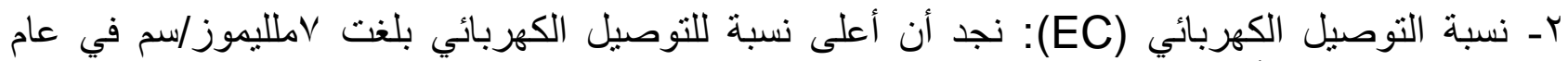

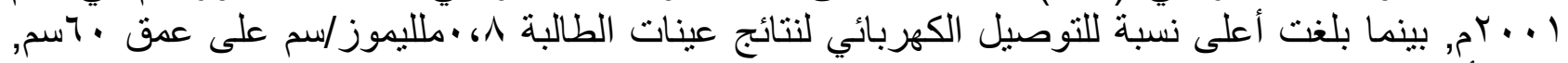

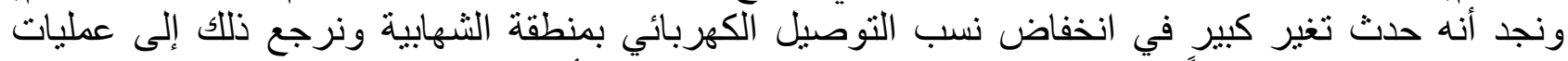

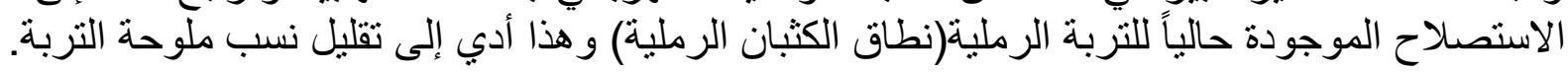

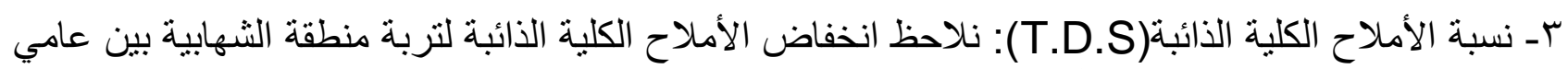

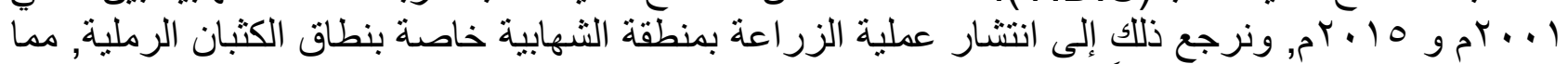

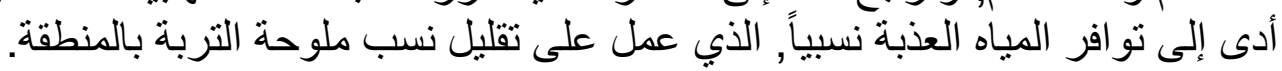

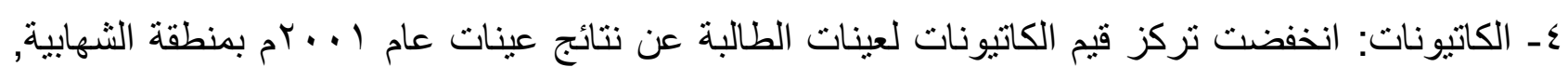

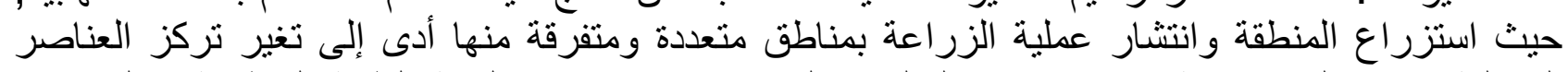

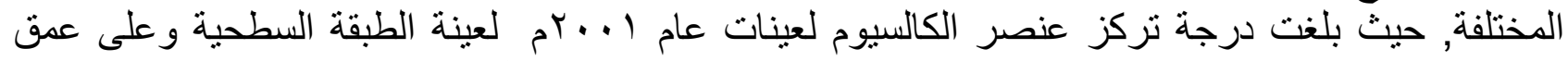

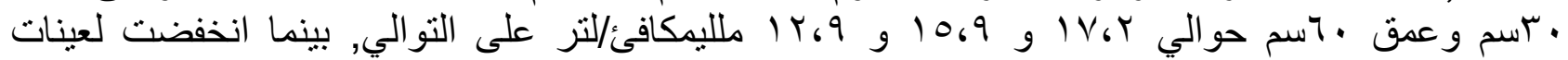

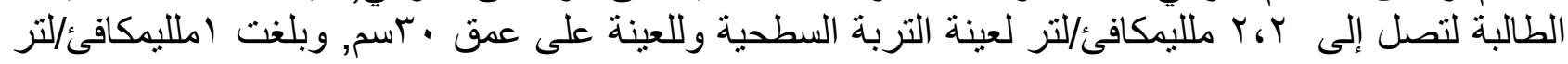

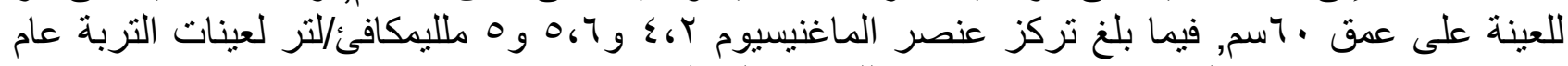

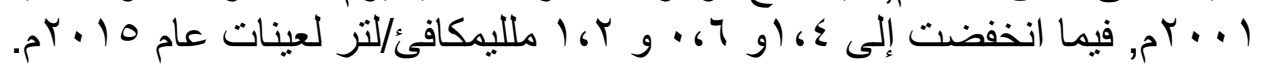

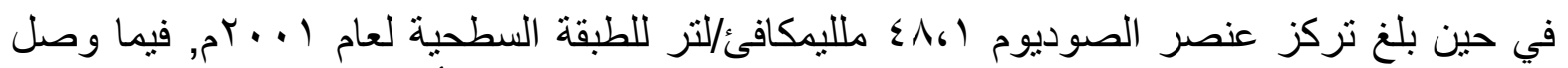

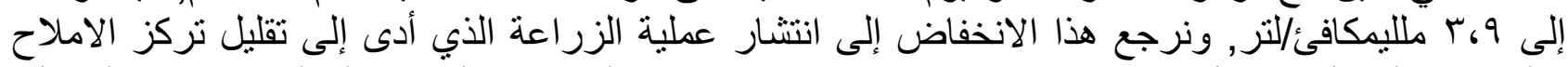

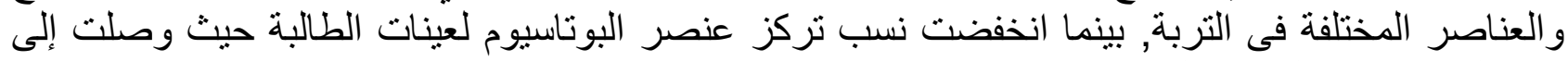

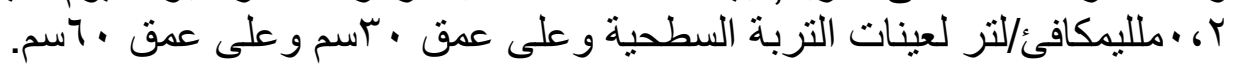

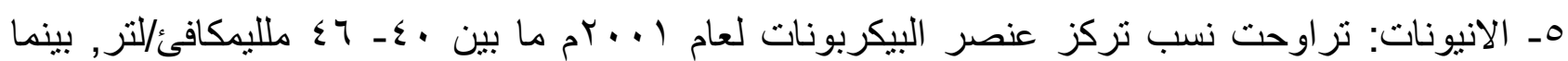

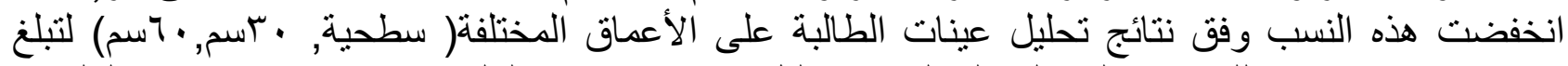

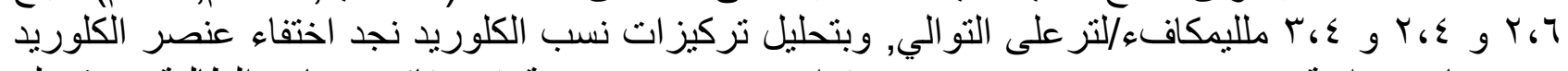

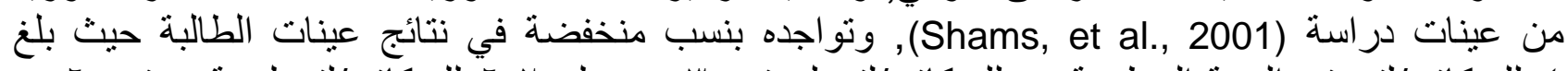

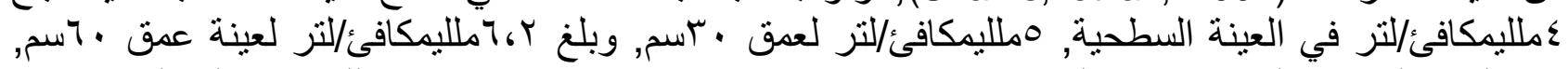

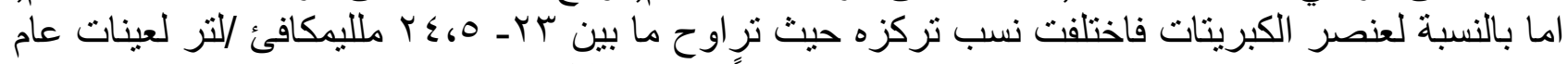

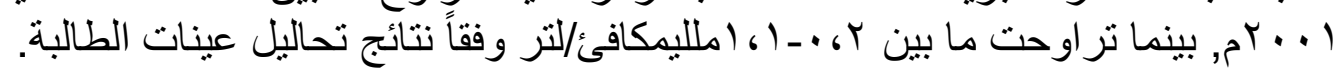

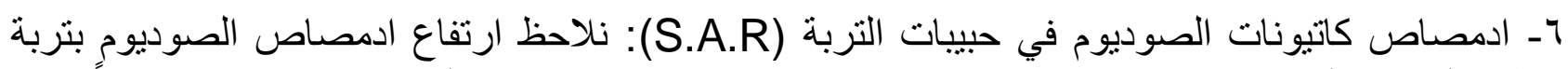

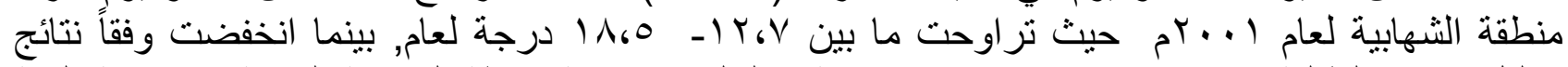

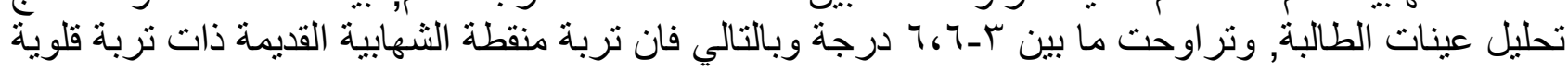

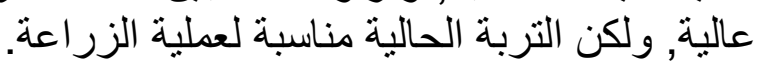

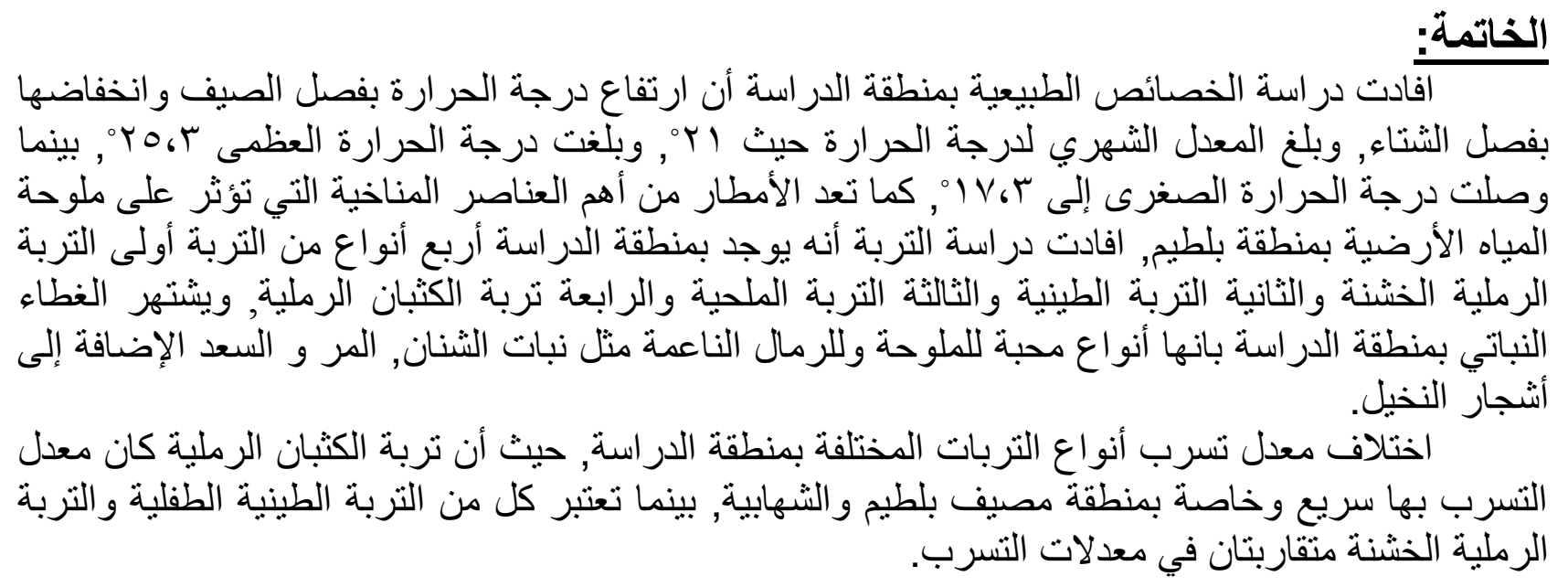


ترتفع درجة ملوحة المياه الأرضية في المناطق القريبة من شاطئ البحر المنوسط وشاطئ بحيرة

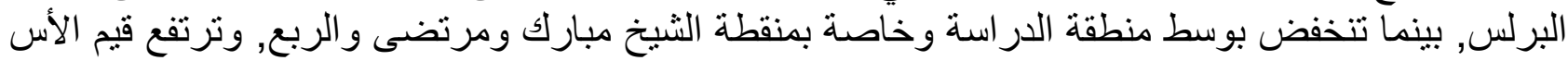

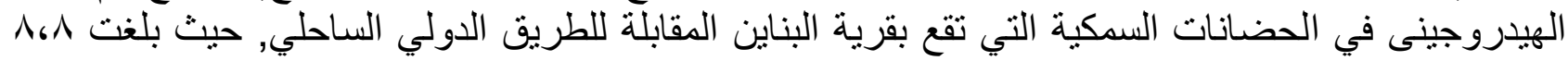
و هذه القيمة مناسبة لإنشاء المز ارع السيات السكية.

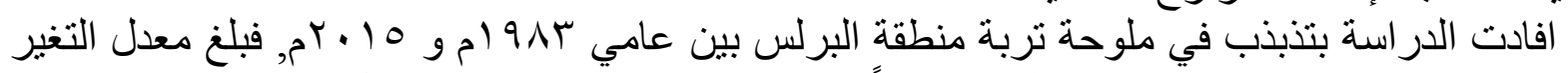

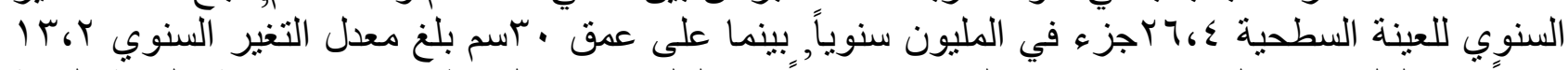

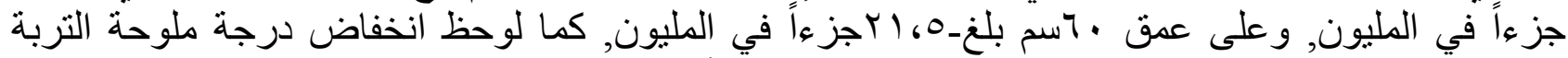

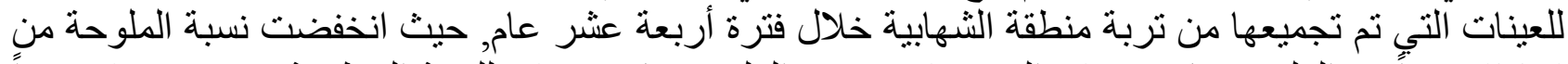

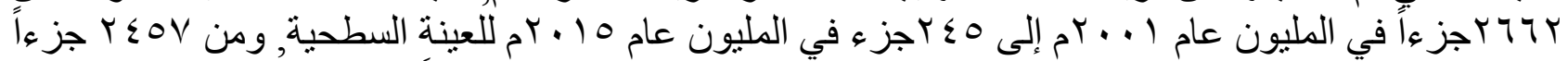

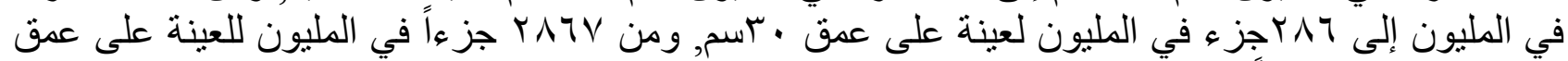

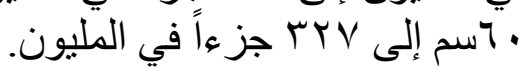

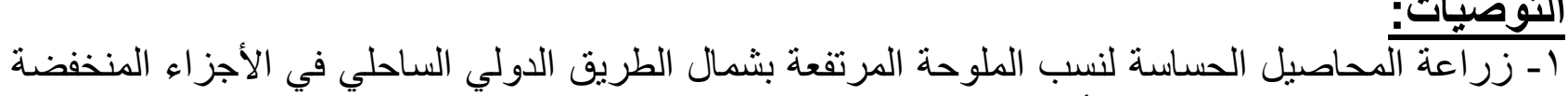

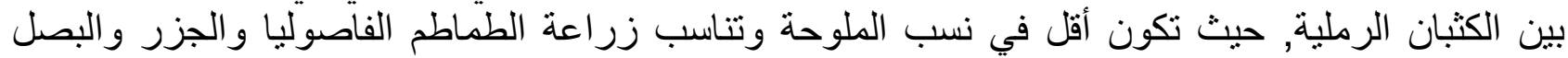

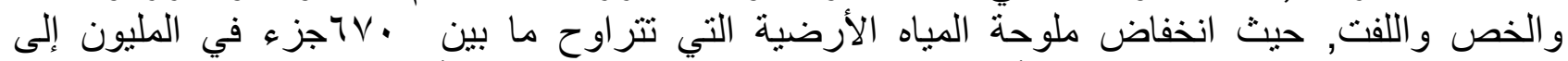

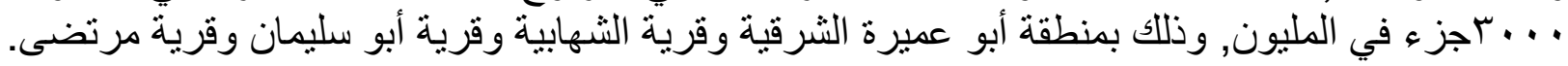

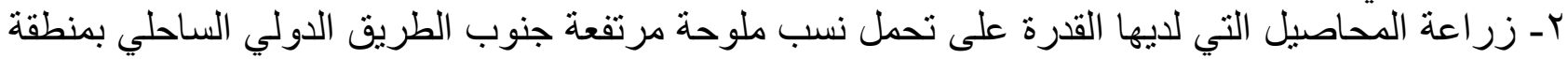

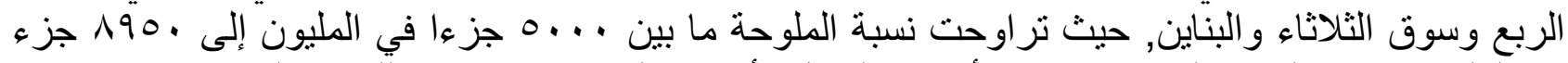

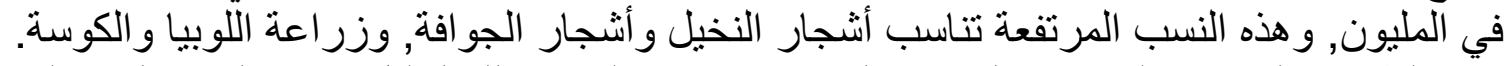

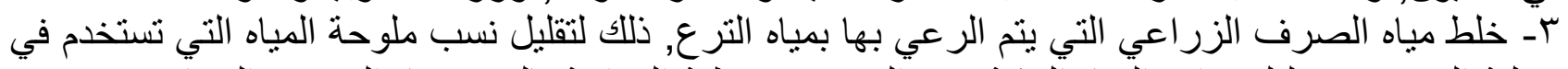

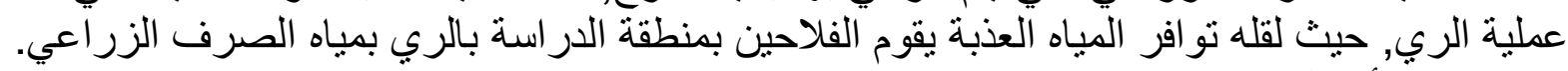

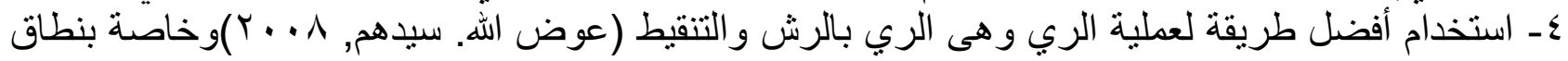

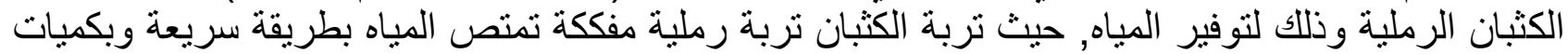




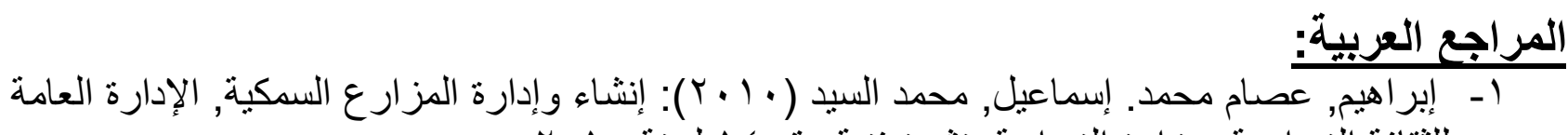

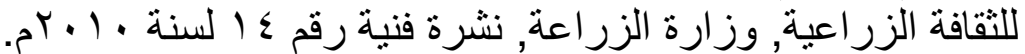

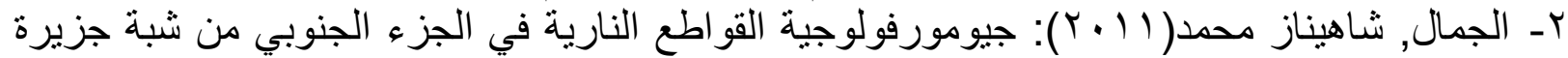
سيناء باستخدام نظم المعلومات الجغر افية, رسالة ماجستير غير منشورة, قسم الجغر افيا, كلية الآداب, جامعة دمنهور.

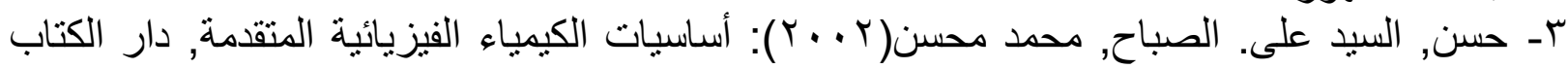
الجامعي, القاهرة.

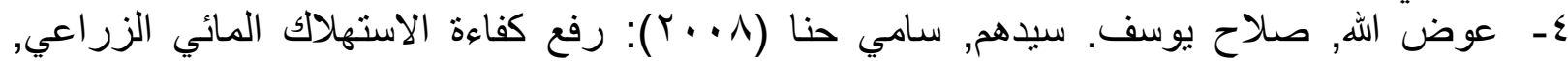

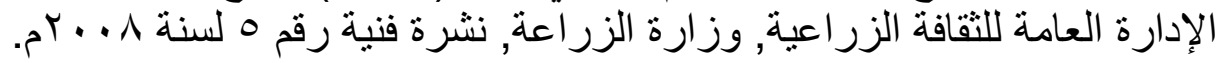

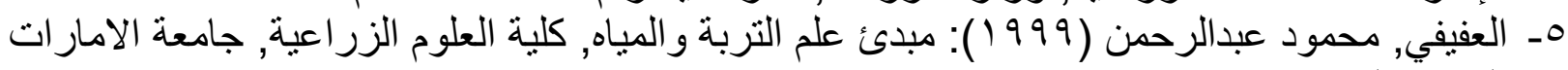
العربية المتحدة.

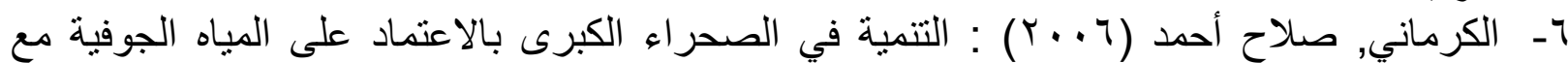
التطبيق على شرق العوينات "دراسة في الجغرافيا البشرية, رسالة ماجستير غير منشورة, قسم

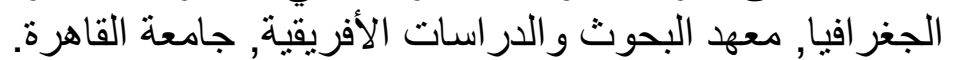

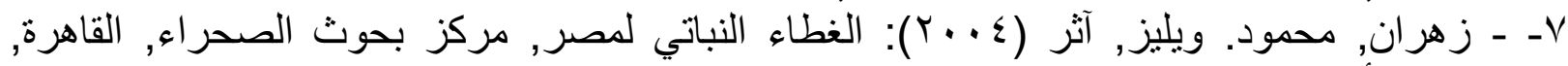
الطبعة الأولى.

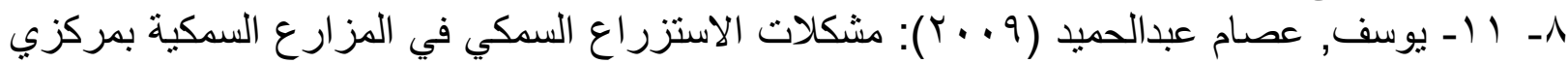

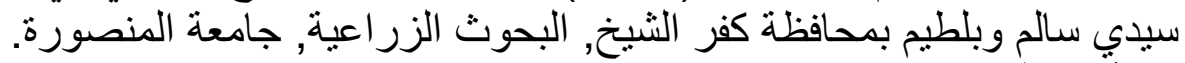

1- Ahmed Osman(1987): Studies on salt affected soils, master of science in soil science, faculty of agriculture, Mansoura university.

2- Shams, et al., (2001): Sorption of sulphate in alkaline soils as affected by wetting and drying processes, j.Agric Res. Tanta university, vol 27, no.3.

3- Abdel-Hafez, et al.,(2008): Effect of irrigation, nitrogen and organic fertilization on soil water relationships of zea maize crop, J.Agric. Sci. Mansoura university, vol 33, no.7. 